\title{
From the Disordered Mind to the Socialized Lived Body: Agoraphobia Through the Lens of a Radical Feminist Phenomenology
}

\author{
by \\ Vesna Lukić
}

A thesis submitted to the Faculty of Graduate and Postdoctoral Affairs in partial fulfillment of the requirements for the degree of

Master of Arts

in

Women's and Gender Studies

Carleton University

Ottawa, Ontario

C 2019, Vesna Lukić 


\begin{abstract}
This thesis explores the potential to reconceptualise agoraphobia through a radical feminist phenomenological framework, moving away from a strictly medicalized understanding of agoraphobic lived experiences and towards a more holistic approach. A radical feminist phenomenological framework is developed by reading Iris Marion Young's account of women's bodily existence in a patriarchal society through Sarah Lucia Hoagland's theoretical framework of "protection and predation". This framework relies on Merleau-Ponty's understanding of embodied subjectivity to argue that women's oppression is an oppression of the lived body. The early lived experiences of agoraphobic women are then read through this theoretical framework, suggesting that agoraphobic women are socialized into aspects of female bodily existence during their early childhoods. The unpredictability of this early childhood familial environment is argued to play a substantial role in the manifestation of this socialization process and, subsequently, in the experience of female bodily existence. This thesis argues that agoraphobic lived experiences arise as a result of this socialization process, which presents an understanding of these experiences as socialized lived bodily experiences, significantly influenced by the oppressive circumstances of women's lives in a patriarchal society. As socialized experiences of the lived body, the conception of agoraphobia as a "disordered" state of the female mind can be challenged.
\end{abstract}


To all the women who came before me...

Without you this thesis would not be possible.

To all the women who will come after me...

Without you this thesis would be meaningless.

To Jean Talerico, whose battle with the patriarchy is hardly theoretical. You inspire me every day.

A special thank you to Diana Majury, for the unwavering belief in my work. 


\section{Table of Contents}

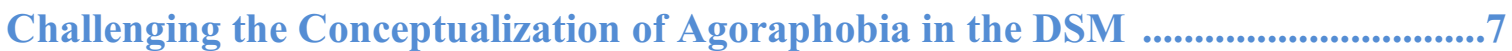

DSM 3: Introducing Agoraphobia as a Mental Disorder..............................................10

Agoraphobia, "Normality" and the "Dysfunctional" Woman .......................................13

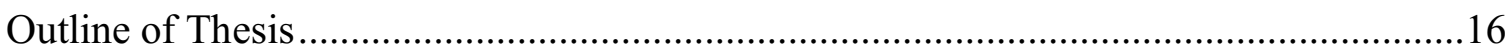

A Review of the Literature: Feminism, Psychiatry and Agoraphobia ........................19

Feminist Engagements on the Nature of Agoraphobia ...............................................19

State of Being: Dis-Order and Agoraphobia in Women ..........................................20

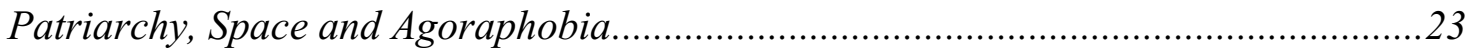

Understanding Agoraphobia: The Feminist Concern with Femininity .......................26

Feminist Analysis of the Psychiatric Classificatory Process ......................................29

Patriarchal Oppression and the Development of Mental Distress ..............................29

Psychiatric Classification and the Regulation of Normative Behavior ........................33

Assembling a Feminist Methodology ...............................................................................38

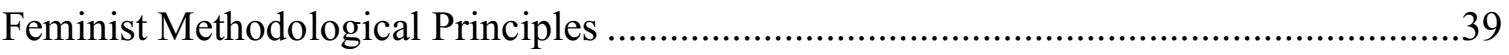

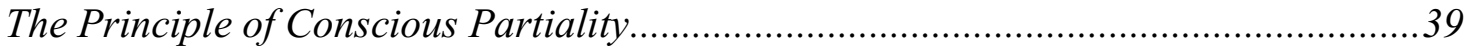

Empowering Women During the Research Process ............................................41

Reducing Hierarchy: The Participatory Model .......................................................43

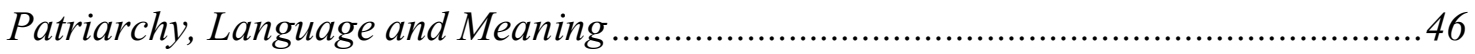

Applying Feminist Principles to the Research Process................................................4

Formulating the Research Project: My Lived Experiences as a Starting Point ............47

Recruiting Agoraphobic Women for the Research Project.......................................49

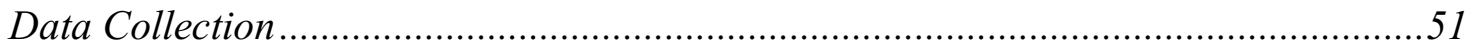


The Feminist Interview

The "Data Analysis" Stage.

Radical Feminist Phenomenology: A Theoretical Development .....

A Revolutionary Impulse: Radical Feminist Theory

Heterosexualism and The Ideology of Protection and Predation .................................64

The Oppression of Women - Which “Women"? ......................................................66

The Relevance of Hoagland's Theory to The Study of Agoraphobia ...........................70

Feminist Phenomenology: On Women’s Lived Bodily Experiences ..............................71

From Merleau-Ponty to Iris Marion Young: Developing a Feminist Phenomenology

Feminist Phenomenology: On the Importance of Agency .........................................76

Engaging Feminist Phenomenology from a Radical Feminist Perspective ......................77

Modifying Feminist Phenomenology's Feminism ................................................... 78

A Radical Feminist Reading of Women's Lived Bodily Experiences ...........................79

Understanding Agoraphobia: A Radical Analysis of Agoraphobic Experiences ......81

Analyzing the Early Lived Experiences of Agoraphobic Women.................................82

Danger and the Socialization of Vulnerability in the Lived Body ..............................83

Threatening the Autonomous Self: Predators, Protectors and the Objectification of the

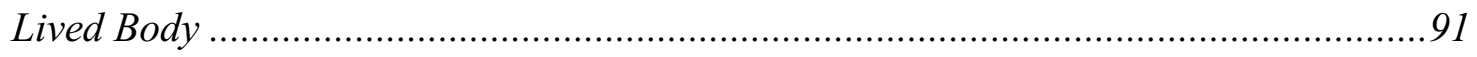

Unpredictability and the Socialization into Female Bodily Existence ...........................97

Socializing the Lived Vulnerable Body in Relation to a Loss of Control .......................98

Unpredictability and Socializing the Lived Body to Seek "Protection".....................101 
Agoraphobia as the Effects of Unpredictable Socialization into Female Bodily Existence

The Agoraphobic Fear of Panic Attacks: A Conditioned Bodily Response ..................104

The Agoraphobic Bodily Experience of Seeking "Safety” from Panic Attacks ..........111

Concluding Remarks ....................................................................................................115

Implications of Research Results on Conceptualizing Agoraphobia............................116

"Treating" the Agoraphobic Woman: Healing or Patriarchal Oppression?.....................118

Bibliography .............................................................................................................................123 


\section{CHALLENGING THE CONCEPTUALIZATION OF AGORAPHOBIA IN THE DSM}

The first edition of the renowned Diagnostic and Statistical Manual of Mental Disorders (DSM), currently considered the authoritative guide to the diagnosis of mental disorders around the world, classified what we now consider an aspect of "normal" sexual behavior as evidence of a pathological condition.1 1952 marked the year that homosexuality was not only considered an abhorrent act in the eyes of the social majority, but also a mental illness. Despite the fact that some homosexuals evidenced a form of mental distress associated with their homosexual behavior, the DSM's claims to homosexuality as pathology primarily relied on an understanding of the supposed "pathological" nature of homosexual behavior. Thus, in order to "cure" the homosexual from his/her "illness", one of the main goals of treatment was to redirect the sexual interest of the homosexual away from the same-sex and towards the opposite-sex, conversion therapy.2

Twenty years after the classification of homosexuality as a mental illness, the American Psychological Association (APA) made a monumental decision to depathologize homosexuality. One of the driving forces behind this depathologization was Kinsey's landmark reports of 1948 and 1953, in which he theorized that human sexual behavior could be represented on a continuum and that homosexual behavior could be seen to fall on this continuum. 3 This argument played a crucial role in

\footnotetext{
1 Drescher, Jack. 2015. Out of DSM: Depathologizing homosexuality. Behavioral Sciences (Basel, Switzerland) 5 (4): 565-75.

2 Cotten, Christopher, and John W. Ridings. 2011. Getting Out/Getting in: The DSM, political activism, and the social construction of mental disorders. Social Work in Mental Health 9 (3): 185.

3 Cotton and Ridings, Getting out/Getting In, 186-187.
} 
normalizing homosexual behavior by suggesting that many individuals experience some form of same-sex attraction. Furthermore, this argument implicitly relied on the assumption that the normality of such behavior indicated that it could not possibly be behavior associated with an "illness". Another key driving force behind this process was the actions of the rising gay liberation movement who frequently targeted the APA's conventions and panels in protest of the claim that they had a mental illness that required serious treatment.

The history of the depathologization of homosexuality reveals that the DSM's classification of homosexuality as a mental illness fundamentally depended on normative understandings of human sexual behavior at the time. Thus, as normative understandings shifted, the idea of homosexuality as a pathology simultaneously was altered. Furthermore, the claims advanced by the gay liberation movement suggested that the pathologization of homosexuality was a way in which the rights and freedoms of LGBT individuals were infringed; their oppression was cemented through the idea that their behavior was an indicator of an illness. This is most evident through the fact that the "treated" homosexual was one who exhibited heterosexual behavior, an individual who abided by the norms of sexuality of the time. The pathologization of homosexual behavior is one way in which the "homosexual" was discriminated against for their sexual preference and behavior.

The revelation of the political nature behind the DSM's classification of homosexuality as pathology, and of the classification process in general, occurred within an environment in which skepticism of the rising prominence of the DSM was already taking hold. This is evidenced by the growing anti-psychiatry movement in the 1960s, 
which Staub argues understood "psychological disorders" as arising from social and political problems.4 An important claim that arose from the anti-psychiatry movement is that madness itself is a plausible and sane reaction to "insane" societal conditions and, as a result, psychiatrists serve as agents of oppression. This view shifted the perception of the "abnormal" onto society and away from the individual, in order to suggest that society was to blame for the mental distress that individuals encountered. Furthermore, the claim by prominent anti-psychiatrist, Thomas Szasz, that the category of mental illness itself is socially constructed, is implicitly accepted by the American Psychological Association. In the prelude to the DSM, a mental disorder is defined as:

"a syndrome characterized by a clinically significant disturbance in an individual's cognition, emotion regulation or behavior that reflects a dysfunction in the psychological, biological or developmental processes underlying mental functioning... an expectable or culturally approved response to a common stressor or loss, such as the death of a loved one, is not a mental disorder." 5 (Emphasis added)

The above definition of a mental disorder represents the view that certain "responses", which indicate a disturbance in an individual's behavior or emotional regulation, cannot be considered mental disorders because society expects that the individual will respond in such a manner. This suggests that those "responses" which society does not expect of the individual, or does not approve of, are deemed to be "mental disorders". Thus, in the

4 Staub, Michael E. 2011. Madness is civilization: When the diagnosis was social, 1948-1980. Chicago: University of Chicago Press.

${ }^{5}$ Van Riel, Raphael. 2016. What is constructionism in psychiatry? from social causes to psychiatric classification. Frontiers in Psychiatry 7. 
same sentence, the drafters of the DSM claim that mental disorders are "real" things, things that arise from some identifiable dysfunction of an individual's biology or psychology, and that they are "things" which are determined by social norms to be indications of this individual dysfunction.

The modern-day societal response to the realization that there was a time, not too far in our past, that homosexuals were given electro-convulsive therapy (ECT) to "cure the gay" is, rightfully outrage. Yet, the simplicity within which the actions of those in the past are morally condemned is not easily transferrable to the actions of those in our present time. Despite the fact that the removal of homosexuality from the DSM played a significant role in the revelation of the highly political nature of the process of classifying "mental disorders", and despite the fact that there is ongoing extensive critique of the process of labelling mental distress as "disorder", there is general societal acceptance of the legitimacy of the DSM. This acceptance is evidenced by the DSM's continuous expansion into previously "normal" behavior, with the newest addition of "tobacco use disorder" and "internet gaming disorder". Although internet gaming disorder is not labelled as an "official" disorder, it is in the DSM under the category "condition for further study".6

\section{DSM 3: INTRODUCING AGORAPHOBIA AS A MENTAL DISORDER}

In 1980, the third edition of the DSM introduced what is now known as agoraphobia (AG). The literal meaning of the term is "fear of the marketplace" based on 
agora, the word for the Greek marketplace.7 True to its history of conceptual issues and constant revisions, the DSM's criteria for agoraphobia have changed frequently since its introduction into the DSM. One particular conceptual issue that has plagued the drafters of the DSM, in relation to defining agoraphobia, has been whether it is its own codeable condition or a secondary condition, linked temporally to a diagnosis of panic disorder. Agoraphobia was initially introduced into the DSM as its own codeable condition which, if it was preceded by a history of panic attacks, would be labelled "Agoraphobia with Panic Attacks". However, DSM 3 - R, the revised version of the third edition of the DSM, defined agoraphobia as a classically conditioned response to situations in which panic attacks had occurred. 8 This resulted in the perception of agoraphobia as a temporally secondary complication to a history of panic attacks or to a diagnosis of panic disorder (PD). The fourth revision of the DSM retained this conceptual linkage and classified three separate diagnosable disorders: panic disorder with agoraphobia, panic disorder without agoraphobia and agoraphobia without panic disorder.

The latest edition of the DSM, published in 2013, conceptually delinks agoraphobia from both panic attacks and panic disorder, suggesting, yet again, that it is its own codeable disorder. Thus, as it currently stands, to be diagnosed with agoraphobia one must exhibit an "intense fear or anxiety prompted by the actual or predicted exposure to 2 or more of the following situations: using public transportation, being in open areas,

7 Cornacchio, Danielle, Tommy Chou, Hayley Sacks, Donna Pincus, and Jonathan Comer. 2015. clinical consequences of the revised dsm-5 definition of agoraphobia in treatment-seeking anxious youth. Depression and Anxiety 32 (7): 502-8. 8 Wittchen, Hans-Ulrich, Andrew T. Gloster, Katja Beesdo-Baum, Giovanni A. Fava, and Michelle G. Craske. 2010. Agoraphobia: A review of the diagnostic classificatory position and criteria. Depression and Anxiety 27 (2): 113-33. 
being in closed-off areas, standing in line or a crowd and being alone outside of the house".9 Furthermore, the diagnostic criteria suggest that an individual must exhibit avoidance behavior in relation to these situations because they fear either panic attacks or anxiety-related symptoms, that the fear must be out of proportion to the possibility of danger and that the fear or avoidance is not better explained by another situational circumstance.10 This latest revision in the conceptual framing of agoraphobia is not without controversy, as some mental health specialists suggest that agoraphobia without a history of panic disorder is rarely seen to occur in clinical settings and that, when it does, it is usually accompanied by subclinical symptoms of panic disorder.

Despite this ongoing conceptual controversy amongst mental health specialists, there is a general consensus that the majority of agoraphobic individuals experience a history of panic attacks and that their avoidance behavior is usually as a result of their fear of experiencing a panic attack. Thus, panic attacks are generally agreed to be a central experience for the agoraphobic individual, regardless of one's stance on the conceptual linkage between agoraphobia and panic disorder. Furthermore, what is often agreed upon is that there is a gendered disparity in the diagnosis of both panic disorder and agoraphobia. According to Foa et al, the majority of people suffering from agoraphobia are women and as a result, agoraphobia can be labelled a "woman's syndrome".11 Furthermore, Foa et al suggest that the percentage rate of agoraphobics who

9 Cornacchio, Danielle, Tommy Chofu, Hayley Sacks, Donna Pincus, and Jonathan Comer. 2015. clinical consequences of the revised dsm-5 definition of agoraphobia in treatment-seeking anxious youth. Depression and Anxiety 32 (7): 503.

10 Cornacchio et al, Clinical Consequences, 504-505.

11 Gelfond, Marjorie. 1991. Reconceptualizing agoraphobia: A case study of epistemological bias in clinical research. Feminism \& Psychology 1 (2): 248. 
are female is somewhere between $65 \%-95 \% .12$ Chambliss and Mason suggest that, regardless of whether clinical or community samples are considered, the chance that agoraphobia will be diagnosed in women is about four times greater.13 Similarly, epidemiologic studies of panic disorder indicate a higher prevalence among females than males, with approximately twice as many women being diagnosed with panic disorder as men.14 Other reports indicate that this gender difference could be as high as the gender difference in the diagnosis of agoraphobia. This gendered disparity has resulted in extensive feminist research into the role of gender in the development of agoraphobia and is a starting point for the framing of this research project from a feminist perspective.

\section{AGORAPHOBIA, "NORMALITY" AND THE "DYSFUNCTIONAL" WOMAN}

According to the definition of agoraphobia in the DSM, an individual's fear of experiencing a panic attack, and their subsequent avoidance of situations which trigger panic attacks, are "symptoms" of a "mental disorder". This claim about the lived experiences of the agoraphobic individual suggests two main things. First, labelling these lived experiences as "symptoms" implies that the fear that agoraphobic individuals experience is "abnormal" or "irrational". This is evident through the DSM's stipulation that, in order to be diagnosed with agoraphobia, one must experience fear that is "out of proportion" to the possibility of danger. Secondly, by suggesting that these lived experiences are symptoms of a "mental disorder", the drafters of the DSM imply that

12 Gelfond, Reconceptualizing agoraphobia, 248.

13 Bekker, Marrie H. J. 1996. Agoraphobia and gender: A review. Clinical Psychology Review 16 (2): 12946.

14 Bekker, Agoraphobia and gender, 129-130. 
they arise as a result of some "...dysfunction in the psychological, biological or developmental processes underlying mental functioning".15

The above should be considered in light of the fact that agoraphobia is predominantly diagnosed in women and has been argued by feminists to be a "woman's disorder". The claim that an agoraphobic individual's experience of fear and avoidance is "abnormal" is in effect a claim that women's experiences with intense fear around certain situations is "unreasonable". Thus, although the claim is on its face gender neutral, the disproportionate diagnosis of agoraphobia in women suggests that it is women's fear responses which are being pathologized. Secondly, the claim that an "individual" develops agoraphobia, as a result of some dysfunction in their psychological or biological constitution, is similarly a claim about knowledge of some "dysfunctional" female psychological or biological process which results in the observed "symptoms".

With the above in mind, I want to raise two main issues. First, the fact that it is women's emotional and behavioral responses which are being judged as "abnormal" suggests that a diagnosis of agoraphobia depends upon an understanding of normative behavioral and emotional responses for women. For example, an individual is considered agoraphobic if they exhibit a fear response which is out of proportion to the possibility of danger. In order to make this claim, there is an implicit understanding of a "proportional", expectable, or "normal" fear response to the "environment" that the agoraphobic woman encounters. Thus, a diagnosis of agoraphobia is fundamentally dependent on an understanding of how women contravene socially acceptable behaviors.

\footnotetext{
${ }^{15}$ Van Riel, Raphael. 2016. What is constructionism in psychiatry? From social causes to psychiatric classification. Frontiers in Psychiatry 7.
} 
Feminists have written extensively on the issue of diagnosing women with "mental disorders" through the evaluation of emotional and behavioral responses as "unreasonable" ones because they contravene patriarchal social norms. These critiques point to the manner in which a diagnosis with certain "mental disorders" is intended to force abidance to normative patriarchal behavior. 16

The second issue that I wish to raise is in relation to the claim that a woman's fear of panic attacks, and avoidance behavior, is a result of some "dysfunctional" female psychological or biological process. There is no evidence to support this claim, rather, there are merely theoretical speculations on a potential biological or psychological dysfunction that could be the reason why women develop agoraphobia. For example, the biological theory of agoraphobia suggests that the "symptoms" of the agoraphobic woman may be caused by an imbalance of certain neurotransmitters in her brain.17 Support for this theory is the effect that certain medications have on increasing or reducing particular neurotransmitters, which subsequently results in a decrease in panic attacks. However, this is hardly evidence for the causal effect of an imbalance of neurotransmitters on the development of agoraphobia.

In light of the fact that a diagnosis of agoraphobia is dependent on an evaluation of women's abidance to socially normative behaviors, and the fact that this diagnosis suggests that women have some "personal" dysfunction for which there is no evidence,

\footnotetext{
${ }^{16}$ Please see the following references for examples: Bankey, Ruth. 2001. La donna é mobile: Constructing the irrational woman. Gender, Place \& Culture 8 (1): 38 and Jimenez, Mary Ann. "Gender and Psychiatry: Psychiatric Conceptions of Mental Disorders in Women, 1960-1994." Affilia 12, no. 2 (1997): 155 and Busfield, Joan and Jo Campling. Men, Women, and Madness: Understanding Gender and Mental Disorder. Washington Square, N.Y: New York University Press, 1996.

17 Margraf, Jürgen, Anke Ehlers, and Walton T. Roth. 1986. Biological models of panic disorder and agoraphobia-A review. Behaviour Research and Therapy 24 (5): 553-67.
} 
this thesis explores a potential radical feminist phenomenological reading of the early lived experiences of agoraphobic women. In particular, I explore the early childhood relational experiences of agoraphobic women and how a radical feminist phenomenological reading of these lived experiences can potentially provide an understanding of the development of agoraphobia in women as influenced by a patriarchal socialization process which socializes the female lived body to respond to the world in a particular manner. This method of understanding agoraphobia allows for the ability to appreciate agoraphobic lived experiences as thoroughly embodied experiences, ones that are experienced within the individual, but also ones which the individual experiences as a result of patriarchal socialization factors. The lack of existence of a biological "dysfunction" can potentially be better understood as a failure to account for these socialization factors.

\section{OUTLINE OF THESIS}

This thesis is divided into five chapters; literature review, methodology, theoretical framework, results and conclusion. The first chapter is a review of the current literature base, that provides a feminist perspective on the psychiatric classificatory process. This review encompasses feminist concerns with the mental disorder of concern in this research project, agoraphobia, as well as other gendered mental disorders such as bipolar and borderline personality disorder. The first section of this review specifically considers feminist engagements with agoraphobia, including the effects of gendered socialization on the development of agoraphobia in women. The second section of this review examines feminist analysis of the psychiatric classificatory process, examining two broad claims that feminists have advanced in relation to this process. First, that it 
fails to consider the role of patriarchal oppression on women's development of mental "disorders" and, secondly, that the process itself regulates women's behavior according to patriarchal norms.

Chapter 2 is an overview of the feminist methodological framework that this research project draws on. Since this project is focused on women, and the role of being raised in a patriarchal environment on the development of agoraphobia, I find a feminist methodology most suitable and appropriate. The first section of this chapter outlines the feminist principles employed, which include the principle of conscious partiality, the importance of empowering women throughout the research process, the use of the participatory model and the need to consider the role of patriarchal language. The second section of this chapter outlines the manner in which I apply the above feminist principles to each stage of the research process. Chapter 3 is an outline of the radical feminist phenomenological framework that I developed for this research project in order to analyze the collected data. In this chapter, I modify Young's feminist phenomenological framework by adding Hoagland's radical feminist theory of protection and predation to Young's analysis of women's lived bodily experiences in a patriarchal society. This allows me to advance the claim that women are socialized into "female bodily existence", which I suggest is the lived experience of the body as a "naturally" vulnerable object.

Chapter 5 presents my research "results", which is the application of my radical feminist phenomenological framework to the themes I developed from my interview data. This particular thematic analysis presents an understanding of the early lived experiences of agoraphobic women as having a significant role in the development of their subsequent agoraphobic "symptomology". When read through a radical feminist 
phenomenology, some of the early lived experiences of agoraphobic women can be seen as aspects of women's socialization into female bodily existence. I argue that this socialization of the female lived body is significantly influenced by an unpredictable home environment. The reading of agoraphobic women's early lived experiences in this manner provides the potential resources to challenge the claim that agoraphobia is a "mental disorder" by understanding agoraphobic "symptoms" as socialized experiences of the lived body, which suggests that they arise from the social (read: patriarchal) and familial environment that agoraphobic women have been raised in rather than from some aspect of dysfunctional female biology. This reading further challenges the claim that agoraphobia is a "mental disorder" through the potential challenge it presents by reconceptualizing agoraphobic lived experiences as bodily experiences, rather than primarily "mental" processes.

Chapter 6 concludes with some tentative implications of the current research on current treatment methods for agoraphobia. Since current treatment methods rely on an understanding of agoraphobia as a specific kind of "mental disorder", challenging this understanding subsequently challenges the assumptions that underpin the effectiveness of these treatment methods. For example, one common method of treatment is SSRI medication, which relies on the understanding that an individual's biology is primarily responsible for their development of agoraphobia. By challenging this claim to the 
importance of biological processes in the development of agoraphobia, the effectiveness of a medical approach is simultaneously challenged.

\section{A REVIEW OF THE LITERATURE: FEMINISM, PSYCHIATRY AND AGORAPHOBIA}

This research project aims to investigate the nature of the "mental disorder" agoraphobia in order to challenge its current conceptualization as an individualized pathological condition in the Diagnostic and Statistical Manual of Mental Disorders-5 (DSM-5). Because I aim to challenge this understanding through a radical feminist phenomenological reading of the lived experiences of agoraphobic women, prior to their development of agoraphobia, this literature review examines existing feminist critiques on the nature of agoraphobia. Although feminists have engaged critically with the DSM's conceptualization of agoraphobia, often arguing that such a conceptualization fails to account for the patriarchal environment within which agoraphobic women have been socialized, agoraphobia has not been examined to the extent that other gendered "disorders" have. A review of how feminist academics have critiqued other gendered disorders is relevant in order to situate this research project within a rich feminist critique of psychiatric classification. The first part of this literature review examines the ways in which feminists have challenged conceptualizations of agoraphobia whereas the second part broadens this review to encompass feminist critiques of the classification of other gendered "disorders".

\section{FEMINIST ENGAGEMENTS ON THE NATURE OF AGORAPHOBIA}

Feminists have engaged critically with the conceptualization of agoraphobia in the Diagnostic and Statistical Manual of Mental Disorders (DSM), often because of the 
finding that agoraphobia is a gendered disorder that occurs mostly in women.18 In comparison to the diagnosis of men with agoraphobia, numerous studies have found that women are diagnosed at double or triple the rate that men are.19 In order to account for this gendered disparity in diagnosis, feminists have focused on understanding the role of being raised in a patriarchal society on the development of agoraphobia in women. In making their claims on the effects of patriarchal socialization on the development of agoraphobia in women, some feminists contend that agoraphobia can be reconceptualised as a disorder related to being a woman in a patriarchal society. Furthermore, building on the understanding that agoraphobic women tend to avoid public spaces, feminist critiques tap into the potential of a feminist geographical analysis in understanding agoraphobia as a disorder related to particular kinds of spaces. Finally, there is an extensive focus on how gender role socialization impacts women's susceptibility to developing agoraphobia, reframing agoraphobia as a disorder fundamentally related to this socialization process.

\section{State of Being: Dis-Order and Agoraphobia in Women}

Feminist literature on agoraphobia has extensively critiqued psychiatric understanding of agoraphobia as an individualized pathology. Feminist scholars have commented on how clinical understandings of agoraphobia have focused too narrowly on individual genetic or family home environments as explanations for the etiology of

18 Bekker, Marrie H. J. 1996. Agoraphobia and gender: A review. Clinical Psychology Review 16 (2): 130135.

19 Gelfond, Marjorie. "Reconceptualizing Agoraphobia: A Case Study of Epistemological Bias in Clinical Research." Feminism \& Psychology 1, no. 2 (1991): 248; Bekker, Marrie H. J. 1996. Agoraphobia and gender: A review. Clinical Psychology Review 16 (2): 129-46; Bondi, Liz and Erica Burman. "Women and Mental Health: A Feminist Review." Feminist Review 68, no. 68 (2001): 6-33; and Turgeon, Lyse, André Marchand, and Gilles Dupuis. "Clinical Features in Panic Disorder with Agoraphobia: A Comparison of Men and Women." Journal of Anxiety Disorders 12, no. 6 (1998): 539-553. 
agoraphobia, resulting in a failure to engage with broader societal and cultural explanations.20 These feminist critiques have greatly contributed to historicizing and contextualizing understandings of agoraphobia. As a result of feminist considerations on expanding an understanding of agoraphobia, beyond an "abnormality" which occurs within the individual, feminists have reconceptualised agoraphobia as a disorder related to being a woman in a patriarchal society.

For example, Davidson presents the argument that agoraphobia can be understood in terms of an experiential intensification of the problems associated with maintaining a stable-self-identity by women in Western society.21 She suggests that women, in general, have difficulty maintaining a stable self-identity because of the "intensely limiting aspects of a masculine social world", such as the expectation of women to be sensitive and responsive to the needs and gaze of others.22 As a result, agoraphobic women's experiences with panic attacks, in this masculine social world, are examples of pathological responses to difficulties all women experience in maintaining a stable self in a patriarchal social environment. Although Bankey similarly draws on a feminist geographical approach, in critiquing an understanding of agoraphobia as a clinical individualized pathology, she suggests that it can be understood as a "fear of the hysterical image", or a fear of "being perceived by others as excessively feminine".23 Her argument suggests that all women have typically been punished and disciplined for

20 Bankey, Ruth. 2001. La donna é mobile: Constructing the irrational woman. Gender, Place \& Culture 8 (1): 42-43.

21 Davidson, Joyce. 2001. Pregnant pauses: Agoraphobic embodiment and the limits of (im)pregnability. Gender, Place \& Culture 8 (3): 283-285.

22 Davidson, Pregnant pauses, 294-295.

23 Bankey, Ruth. 2001. La donna é mobile: Constructing the irrational woman. Gender, Place \& Culture 8 (1): 38 . 
hyper-femininity but that agoraphobic women experience this fear of punishment far more intensely than the "average" women would, which indicates the pathological nature of their experience.

Jacobson presents an interesting argument for the consideration of agoraphobia as a woman's experience of a flawed relationship with home, which results in her inability to fully function as an agent in the world.24 Jacobson locates this flawed relationship with home in the interpersonal struggles of the agoraphobic woman's developmental life in her first home, which structured her lived body as vulnerable outside of the home. She suggests that these interpersonal struggles can be related to women's cultural conditioning into their gendered roles and, as a result, agoraphobia can be understood as an "emblematic expression of the ongoing pathology of being a woman in contemporary society". 25 Bordo considers the body to be a medium of culture and suggests that agoraphobia can be seen as a "virtual parody of twentieth century constructions of femininity". 26 Thus, she argues that agoraphobia is a disorder that results from the construction of femininity on the female body in hyperbolic terms.

The above feminist critiques have reconceptualised agoraphobia as an illness which arises from the oppressive societal conditions within which women find themselves, rather than an individualized pathology. Despite the importance of such a reconceptualization in highlighting the need to engage with societal norms and structures in order to alleviate the structural conditions which contribute to the development of

24 Jacobson, Kirsten. 2011. Embodied domestics, embodied politics: Women, home, and agoraphobia. Human Studies 34 (1): 1-2.

25 Jacobson, Embodied domestics, 1.

26 Bordo, Susan, 1947. 1993. Unbearable weight: Feminism, western culture, and the body. Berkeley: University of California Press, 165. 
agoraphobia in women, there has rarely been an attempt to reconceptualise the understanding of agoraphobia as an "illness". The importance of considering the argument that agoraphobia may not be a mental illness lies in the observation that there is currently no evidence to support the existence of agoraphobia as an individualized pathology. As with many "disorders" in the DSM, there are mostly psychiatric speculations on the "etiology" of agoraphobia. Without "evidence" for its existence as a mental illness, feminists who claim that agoraphobia is a "woman's disorder" rely on the implicit psychiatric assumption that agoraphobic women's fear responses are pathological. This research project specifically challenges this psychiatric assumption by suggesting that agoraphobic experiences are socialized responses to the effects of an unpredictable familial home on women's socialization in a patriarchal environment. Although I do not suggest that this rules out the possibility of a pathological condition, I do want to argue that assuming pathology within women is something that feminists should be wary about, especially considering their own arguments on the role that psychiatry plays in maintaining women's oppression.

\section{Patriarchy, Space and Agoraphobia}

Feminist research on agoraphobia has engaged extensively with a reflection on how a feminist spatial analysis can inform a greater understanding of agoraphobia as related to the effects of patriarchy on women's experiences in public spaces. This spatial analysis is driven by the psychiatric understanding of agoraphobia as a spatially mediated disorder; it is generally understood that agoraphobic women tend to avoid certain spaces in fear of a potential panic attack. Davidson contends that the social nature of public spaces subjects all women to the "masculinist gaze" and to "misogynist imagery", which 
make it difficult to maintain a stable self-identity.27 Since agoraphobic women tend to experience panic attacks in these public spaces, and feel more "secure" in the space of the home, Davidson suggests that the patriarchal nature of public spaces can aid in an explanation of the development of agoraphobia in women. Bankey suggests that agoraphobic women's fears, and resultant avoidance behaviors, can be understood to result from their fear of being perceived as a "hysterical woman" in public spaces because it is within these spaces that women have traditionally been disciplined and punished for exhibiting "hysterical" behaviors.28 Thus, according to Bankey, agoraphobia is fundamentally related to the patriarchal control and discipline of the behavior of women in public spaces.

Gelfond argues that women's development of agoraphobia can be understood as resulting from their socialization into aspects of femininity which make it difficult for them, and which makes them fearful of, the navigation of public spaces. Gelfond further argues that all women are socialized to have this difficulty and, as a result, “...the only distinction between women clinically labelled agoraphobic, and women who have not been labelled as such, is the degree of environmental restriction." 29 Similarly, Van Zuuren suggests that women are socialized to be unable to maintain their own identities in public spaces and that, as a result, they become agoraphobic because they have only been socialized to function with emotionality in the private sphere30. Finally, although

27 Davidson, Joyce. Phobic Geographies: The Phenomenology and Spatiality of Identity. Burlington, VT: Ashgate, 2003.

28 Bankey, Ruth. "La Donna é Mobile: Constructing the Irrational Woman." Gender, Place \& Culture 8, no. 1 (2001): 37-54

29 Gelfond, Reconceptualizing Agoraphobia, 248-250.

30 Bekker, Marrie H. J. "Agoraphobia and Gender: A Review." Clinical Psychology Review 16, no. 2 (1996): 129-146. 
Jacobson seeks to critique the understanding of agoraphobia as a fear of "outside spaces", her feminist phenomenological approach suggests that an understanding of the development of agoraphobia in women is necessarily a spatial one. She claims that to understand the development of agoraphobia in women one must understand how their lived bodies have been conditioned to function within the home. As a result, women's development of agoraphobia is linked to their inability to venture outside of the home, into the public sphere.31

Feminist geographical contributions, to an understanding of the gendered disparity in the occurrence of agoraphobia, tend to focus attention on the problematic relationship that agoraphobic women have with public spaces. These contributions have significantly advanced a feminist understanding of why agoraphobic women tend to fear having panic attacks in certain spaces. However, these feminist concerns tend to focus heavily on the manifestation of agoraphobic women's fear and avoidance behaviors in public spaces, neglecting to consider experiences of panic and fear within the home. Nor does this feminist concern with public spaces aid in an explanation as to why agoraphobic women tend to, on the whole, feel more comfortable in public spaces with a "comfort person". Holmes addresses this issue with his notion that the central dichotomy in agoraphobia is not that between public and private space, but between threat and security.32 According to Holmes, the "home" represents security because that is where the agoraphobic woman's "safe person" can be found, usually their primary caregiver.33 My

31 Jacobson, K. (2011). Embodied domestics, embodied politics: Women, home, and agoraphobia. Human Studies, 34(1), 3-7.

32 Holmes, Joshua. "Space and the Secure Base in Agoraphobia: A Qualitative Survey." Area 40, no. 3 (2008): 375-376.

33 Holmes, "Space and Secure Base", 380. 
research project develops Holmes' argument that the central dichotomy in agoraphobia is between threat and security by arguing that agoraphobic women's fear responses arise from the patriarchal socialization of women to experience the body as vulnerable when without "protection", understood as being in the proximity of a "protector" or being within the "safe" space of the home.

\section{Understanding Agoraphobia: The Feminist Concern with Femininity}

Feminist scholars' attempts to explain the disproportionate number of women diagnosed with "agoraphobia" has led to studies which focus on the role of gender as an explanatory variable in women's development of agoraphobia. Particularly, scholars have argued that gender role socialization in women is crucial to understanding the development of agoraphobia. For example, Gelfond argues that women develop agoraphobia as a result of their socialization into aspects of femininity, such as the early protectiveness of girls and a lack of facilitation of autonomous functioning outside of the home.34 Similarly, Jacobson prioritizes gendered concerns when she suggests that the cultural constructions and conditioning of girls into femininity are relevant in an understanding of women's development of agoraphobia. Jacobson argues that girls are trained into making a "stable, inward turning home" which results in structuring the agoraphobic lived body as lacking autonomous functioning outside of the home. 35

The earliest critiques of agoraphobia which consider the impact of gendered roles in the development of agoraphobia in women have been outlined by Reuter.36 She looks

34 Gelfond, Reconceptualizing Agoraphobia, 251-252.

35 Jacobson, K. (2011). Embodied domestics, embodied politics: Women, home, and agoraphobia. Human Studies, 34(1), 7-8

36 Reuter, Shelley Zipora. 2001. 'The very opposite of calm': A socio -cultural history of agoraphobia. ProQuest Dissertations Publishing. 
at the work of Gardner and Brown who argue that gender ideologies make public spaces more difficult for women to navigate and do not allow women to participate fully and equally in public life. McSpurren also takes up the issue of gender roles by arguing that the diagnostic category of agoraphobia has served to confirm the social construction of femininity. Reuter contributes to this discussion by arguing that agoraphobia can be seen as a means to force the imperative of "true womanhood" on women in order to thwart the expansion of women's rights. 37

Bekker critiques the current literature on gender and agoraphobia arguing that the "current sex-role approach to agoraphobia is too narrowly focused and that there should be a broad-spectrum sex role approach". 38 She suggests that current literature focuses too much on women's socialization into dependence and "low-autonomy" and that this focus fails to explain why only a minority of women develop agoraphobia. The feminist focus on the role that gendered socialization plays in women's development of agoraphobia developed from the realization that some of the core "symptoms" of agoraphobia are strikingly similar to the ways in which women are taught to "properly" behave in a patriarchal society. This research project builds on these feminist claims by situating gendered socialization within the relationship of heterosexualism, as outlined by Hoagland. By viewing agoraphobic lived experiences through this lens, a greater

37 Reuter, Shelley Zipora. 2001. 'The very opposite of calm': A socio -cultural history of agoraphobia. ProQuest Dissertations Publishing. 38 Bekker, Marrie H. J. "Agoraphobia and Gender: A Review." Clinical Psychology Review 16, no. 2 (1996): 130-134. 
appreciation of how aspects of women's patriarchal socialization contribute to their development of agoraphobia can be gleaned.

Feminist analysis of the "mental disorder" agoraphobia have greatly contributed to an understanding of why women develop agoraphobia at greater rates than men. Their arguments have focused on reconceptualising agoraphobia as a "woman's disorder", on the relevance of patriarchal space in the development of agoraphobia, and on the ways in which gender role socialization contributes to agoraphobic "symptomology". Despite these significant contributions, and with the exception of Davidson's phenomenological approach, feminist analysis has not significantly engaged with the lived body in its analysis of agoraphobia. The relevance of such an approach lies in the fact that agoraphobic fear and avoidance behaviors rely on the perception of the body as in danger. As such, an approach that considers how this perception may arise is relevant. Furthermore, since the oppression of women occurs at the level of subjectivity, shaping the way the subject views the world, feminists would be well placed to consider the role this plays in the development of agoraphobic lived subjectivities. As such, this research project has been inspired by Davidson's accurate observation that the lived bodily experiences of agoraphobia are quite similar to the manner in which women have been socialized to experience an unstable sense of embodied self.39 I build off on this 
observation through an application of a radical feminist phenomenology to an understanding of women's lived experience with agoraphobia.

\section{FEMINIST ANALYSIS OF THE PSYCHIATRIC CLASSIFICATORY PROCESS}

Feminist critiques of psychiatric nosology can be traced back to the 18 th and $19_{\text {th }}$ century discussion of women's hysteria to the more modern feminist engagement with the classifications in the Diagnostic and Statistics Manual of Mental Disorders ("the DSM"). Despite the fact that early psychiatric classification schemes differed greatly in substance from modern nosology's, particularly with the increasingly important role of science in the determination of what actually constitutes a "mental disorder", feminist critiques have consistently centered around two main ideas: that the classification process has generally failed to account for the role of oppressive societal factors in the occurrence of mental disorders, and that this process has resulted in the control/regulation of women's behavior, usually in accordance with normative femininity.

\section{The Role of Patriarchal Oppression on the Development of Mental Distress}

Feminist engagements with psychiatric classification have advanced the argument that the process of classifying women's mental distress as pathology has neglected consideration of the effect of oppressive societal conditions in the development of mental distress in women. As Dodd writes, the importance of considering oppressive social conditions has been in the forefront of feminist analysis because feminists' understand that the pathologization of women's behavior maintains and reinforces these oppressive societal conditions.40 As with feminist critiques of agoraphobia as a "mental disorder",

40 Dodd, Jenifer. 2015. "The name game": Feminist protests of the DSM and diagnostic labels in the 1980s. History of Psychology 18 (3): 312-23. 
feminist engagements with psychiatric classification have argued either that oppressive societal conditions contribute to the development of disorders or to the development of mental distress that has been incorrectly labelled as a "disorder".

Feminist critiques of psychiatric classification argue for a consideration of the mental distress, associated with certain disorders, as arising from oppressive societal conditions. In this manner, they suggest that claims to pathology hide the essentially social nature of mental distress. For example, Shaw and Proctor argue that the diagnosis of borderline personality disorder (BPD) "distracts from the aetiological importance, for psychological distress, of the experience of childhood sexual abuse".41 They argue that at least 70 percent of women with BPD have been sexually abused as children and that the symptoms of BPD can be better understood as "adaptive reactions to early relational traumas".42 Reavey and Warner similarly suggest that BPD can be "understood as the social embodiment of childhood sexual abuse". 43 They argue that the symptoms characteristic of BPD, such as self-destructive and stormy interpersonal behaviors, are attempts to cope with the rage and guilt associated with the symbolic re-experiences of trauma. By considering how some women's experiences of sexual abuse contribute to an

41 Shaw, Clare, and Gillian Proctor. 2005. I. women at the margins: A critique of the diagnosis of borderline personality disorder. Feminism \& Psychology 15 (4): 486.

42 Shaw and Proctor, Women at the Margins, 486-487.

43 Sam Warner and Tracy Wilkins, "Diagnosing Distress and Reproducing Disorder: Women, child sexual abuse and "borderline personality disorder"' in New Feminist Stories of Child Sexual Abuse, ed. Paula Reavey and Sam Warner (London, Routledge, 2003) 167-182. 
understanding of BPD symptoms these authors provide alternative ways to deal with this mental distress, ways that primarily focus on relational traumas.

Mauthner argues that the medicalization of post-partum depression (PPD) essentially hides the social nature of the mental distress associated with this disorder. 44 She suggests that the pressures on mothers to be "perfect", and to abide by the norms of motherhood, significantly influence women's emotional states. As a result, she suggests that the medicalization of these social problems results in placing blame on the individual mother for her "problems" rather than addressing the "...wider sociopolitical and ideological context and structures in which these mothers' experiences are embedded". 45 Mauthner's important contributions to an understanding of the social nature of PPD are reinforced by Chrisler and Johnston Robledo's argument that it is the institution of motherhood that has an etiological role in the development of the distress associated with PPD and that, as a result, PPD can be thought of as a "normal grief reaction to a significant loss of identity" associated with taking on the identity of "mother".46

Feminist scholars have also presented the argument that aspects of women's patriarchal oppression contribute to the development of mental disorders. These arguments differ from the ones above because they assume that women's mental distress is pathological and that oppressive social circumstances play a causal role in the development of this pathology. For example, McSweeney argues that women's

44 Mauthner, Natasha. "I. Towards a Feminist Understanding of 'Postnatal Depression." Feminism \& Psychology 3, no. 3 (1993): 350-355.

45 Mauthner, Natasha. "I. Towards a Feminist Understanding of 'Postnatal Depression." Feminism \& Psychology 3, no. 3 (1993): 350-352.

46 Joan C. Chrisler and Ingrid Johnston-Robledo, "Raging Hormones? Feminist Perspective on Premenstrual Syndrome and Postpartum Depression" in Rethinking Mental Health and Disorder: Feminist Perspectives, ed Mary Balllou and Laura S. Brown (New York, N.Y: Guilford Press, 2002) 174-180. 
socialization to experience the self as relational, which requires them to be selfsacrificing, leads to their development of depression. 47 McSweeney suggests that it is oppressive patriarchal norms, which govern the creation of the "female self", that contribute to the development of the symptoms of depression. Similarly, Farrell and Cacchioni argue that the distress associated with female sexual pain, which is the main diagnostic criteria for female sexual dysfunction (FSD), is exacerbated by women's desires to adhere to norms of heterosexuality.48 Thus, according to Farrell and Cacchioni, FSD is a legitimate disorder and aspects of this disorder can be seen to arise from oppressive societal factors.

Lester considers BPD a disorder of relationship where most people "diagnosed with BPD grew up in situations where their very existence as a person, with independent thoughts and feelings, was invalidated". 49 Lester links this early childhood environment with the role that gender plays in undermining women's independent existence in order to argue that women are more prone to the development of this disorder. Finally, Svanaeous suggests that anorexia nervosa develops as a result of societal norms of beauty which result in women's relationships with their bodies as "other" and "object".50

Feminist arguments that have considered the role of oppressive societal factors in the development of mental disorders have greatly contributed to challenging aspects of

47 Sarah McSweeney, "Depression in Women" in Bias in Psychiatric Diagnosis, ed. Paula J. Caplan and Lisa Cosgrove (Lanham, Md: Jason Aronson, 2004) 183-186.

48 Farrell, Janine and Thea Cacchioni. "The Medicalization of Women's Sexual Pain." Journal of Sex Research 49, no. 4 (2012): 329-330.

49 Lester, Rebecca J. "Lessons from the Borderline: Anthropology, Psychiatry, and the Risks of being Human." Feminism \& Psychology 23, no. 1 (2013): 74.

50 Svenaeus, Fredrik, Institutionen för kultur och lärande, Centrum för praktisk kunskap, and Södertörns högskola. "Anorexia Nervosa and the Body Uncanny: A Phenomenological Approach." Philosophy, Psychiatry, \& Psychology 20, no. 1 (2013): 81-91. 
the DSM's classification process. While some have argued that classifying mental distress as a disorder is oppressive to women, others have argued that failing to consider the role of oppressive norms results in difficulty in treating certain disorders. Future feminist analysis would benefit from explicitly linking the societal factors they consider to broader oppressive patriarchal structures. This would greatly facilitate an appreciation of these arguments by non-feminists, who may not be familiar with central feminist tenets. This research project builds on these feminist critiques by arguing that the claim to agoraphobia as a pathology essentially hides the fact that the symptoms of agoraphobia can be understood as conditioned bodily responses to agoraphobic women's unpredictable socialization into female bodily existence. Because this female bodily existence is the embodiment of the oppressive ideological framework of protection and predation, which is the way in which the relationship of heterosexualism manifests, I argue that agoraphobic lived experiences are significantly influenced by the manifestation of an oppressive ideology meant to maintain women's subjugation to men.

\section{Psychiatric Classification and the Regulation of Normative Behavior}

Feminist critiques of psychiatric nosology have engaged with how women's behavior is controlled and/or regulated by the process of psychiatric classification. Feminists have argued that the process of labelling women's mental distress as psychiatric disorder plays a crucial role in ensuring that women abide by certain normative behaviors; often the discussion is focused on normative femininity. These arguments are an extension of feminist arguments that patriarchal oppression leads to the development of women's mental distress because, in order to make this claim, the idea that this distress is a pathology must be radically disturbed. For example, feminists often 
make reference to the ways in which psychiatric conceptions serve to regulate and control women's behavior according to prevailing social norms. Chesler's seminal work entitled "Women and Madness" presents the argument that mental illness as a category regulates women's behavior according to sex-role expectations. Building on two major foundations, the writings of anti-psychiatrists and the theorization of social roles, she argues that women are labelled as mentally ill for both fully acting out their sex roles and for deviating too far from them.51 For example, Chesler theorizes that women who are diagnosed with depression are punished for their "conditioned and socially approved selfdestructive behavior". Thus, according to Chesler, the category of depression is an example of the labelling of women as mentally ill when they fully act out their sex-role.

Jimenez and Showalter present a similar argument that psychiatric conceptions serve to regulate women's behavior according to prevailing social norms of femininity. Both authors, however, provide an historical account of psychiatric theorization about women from the 19 th century onwards. They present a fascinating account of how the decline and subsequent rise of certain disorders were fundamentally linked with changes in society's conceptualizations of gender. Jimenez suggests that "the 19 th century saw a belief in an irreducibly biological basis for women's mental and emotional functioning" whereas a focus on sexuality then shifted the discussion to moral and psychological aspects.52 Finally, Busfield presents a fascinating argument on how the category of mental illness is constitutive of certain ideas about rationality and agency. She suggests

51 Chesler, Phyllis. Women and Madness. 1st, rev. and updated. New York, N.Y: Palgrave Macmillan, 2005.

52 Jimenez, Mary Ann. "Gender and Psychiatry: Psychiatric Conceptions of Mental Disorders in Women, 1960-1994." Affilia 12, no. 2 (1997): 155. 
that the realm of mental disorder is gendered because it is one which suggests that the actions of the individual arise from a being incapable of agency and rationality (read Woman). 53

Feminists have broadly theorized how psychiatric conceptions regulate women's behavior according to normative femininity. They have also theorized the role of specific psychiatric disorders in regulating various aspects of women's behavior. For example, borderline personality disorder has been written about extensively due to the finding that it is diagnosed in women far more frequently than in men and because its symptoms, often quite glaringly, appear to be representations of exaggerated femininity. Ussher writes extensively on how a diagnosis of borderline personality disorder (BPD) is crucial to the regulation of behaviors in women who are often deemed to be "difficult".54 She argues, similarly to Chesler, that BPD regulates the behavior of women who both contravene normative femininity and who abide too closely to it. For example, common "symptoms" of BPD include being demanding, angry and aggressive, which contravene societally acceptable behavior for women. Shaw and Proctor suggest that the act of diagnosing BPD relies on an understanding of the appropriateness of women's emotions in reference to a norm of rationality and individuality. 55

Two other commonly researched gendered disorders are late-luteal phase dysphoric disorder (LLPDD) and pre-menstrual dysphoric disorder (PMDD). Caplan et

\footnotetext{
53 Busfield, Joan and Jo Campling. Men, Women, and Madness: Understanding Gender and Mental Disorder. Washington Square, N.Y: New York University Press, 1996.

54 Ussher, Jane M. "Diagnosing Difficult Women and Pathologising Femininity: Gender Bias in Psychiatric Nosology." Feminism \& Psychology 23, no. 1 (2013): 63-69.

55 Shaw, Clare and Gillian Proctor. "I. Women at the Margins: A Critique of the Diagnosis of Borderline Personality Disorder." Feminism \& Psychology 15, no. 4 (2005): 484.
} 
al suggest that the numerous methodological errors that plague the scientific research on the classification of LLPDD reveal the category as regulating women's behavior according to sex-role appropriate behavior.56 In relation to PMDD, Caplan and Cosgrove argue that its construction plays a significant role in the control and monitoring of women's behavior according to a rigid stereotypic model of femininity. They argue that such a diagnosis achieves this goal by encouraging women to monitor their own affective and bodily states for signs of "disorder".57 These signs include feeling "overly sensitive" or being "persistently angry and irritable", all of which can be argued to be socially "unacceptable" behaviors for women to embody.

The arguments advanced by feminist scholars about the role that psychiatric classification plays in the control and regulation of women's behavior have been crucial to an understanding of the ways in which psychiatry colludes with patriarchy to maintain obedience to social norms. A couple of authors have further developed these claims to account for the manner in which women themselves act to reproduce what have been labelled as "symptoms" of a psychiatric disorder, subsequently monitoring their own adherence to normative femininity. This shifts the argument away from a simple claim that psychiatry as an institution monitors and controls women's behaviors and actions and towards a more nuanced account of the ways in which women play an active role in this process. For example, Ussher argues that there are "regimes of objectified knowledge that work to construct PMDD" and that ultimately regulate individual women through a

56 Caplan, Paula J., Joan McCurdy-Myers, and Maureen Gans. "Should 'Premenstrual Syndrome' be Called a Psychiatric Abnormality?" Feminism \& Psychology 2, no. 1 (1992): 27.

57 Lisa Cosgrove and Paula J. Caplan, "Medicalizing Menstrual Distress" in Bias in Psychiatric Diagnosis, ed. Paula J. Caplan and Lisa Cosgrove (Lanham, Md: Jason Aronson, 2004) 221. 
process of subjectification. According to Ussher, women are involved in the process of regulating the boundaries of idealized femininity by reproducing specific narratives about their experiences as disorders of the reproductive body. 58

While these claims provide important insights, the suggestion that psychiatric classification maintains women's obedience to normative femininity is simplistic. It conflates the role of psychiatry with the role of patriarchy by arguing that psychiatry exists to maintain the patriarchal oppression of women. Although it is certainly the case that psychiatry has a role in maintaining women's oppression, this conflation fails to account for the ways in which providing a diagnosis and treatment do have a role in alleviating women's mental distress and suffering. Furthermore, this conflation fails to account for other ways in which psychiatry may be complicit in the maintenance of oppressive societal conditions, ones not directly related to patriarchal power. I argue that psychiatry, through the labelling of agoraphobic mental distress as "disorder", plays a role in maintaining women's subjugation but also in obscuring other problematic familial relations. Since I argue that agoraphobic lived experiences are bodily experiences, ones thoroughly experienced within the individual, I allow for the consideration that psychiatry may play a relevant role in alleviating the mental distress that agoraphobic 
women suffer without arguing that psychiatric treatment is the "cure" to an individual's suffering with agoraphobia.

\section{ASSEMBLING A FEMINIST METHODOLOGY}

Mies writes, “...there is a contradiction between the prevalent theories of social science and methodology and the political aims of the women's movement". 59 Feminists have critiqued traditional methodological approaches for their adherence to principles that are oppressive to women, principles that seemingly contradict the purpose of the women's movement itself. These critiques are of three main "kinds": philosophical, moral and practical.60 Philosophical critiques have examined the pretense of value free science, and the presumption of objectivity, whereas moral critiques have criticized the resulting objectification and exploitation of women. On a practical level, feminists have argued that there are distortions of knowledge that occur as a result of the hierarchical nature of dominant methodological approaches. These critiques point to the necessity of feminist methodological guidelines in order to ensure that feminist scholarship does not contribute to the creation of research which is either oppressive to women or distorts their lived experiences because of its hierarchical nature.

This research project seeks to conduct research which contributes to the empowerment (read: liberation) of women from their oppressive patriarchal conditions.

59 Maria Mies, “Towards a Methodology for Feminist Research” in Theories of Women's Studies, ed. Gloria Bowles and Renate Duelli Klein (London; Boston: Routhledge \& Kegan Paul, 1983), 117-118. 60 Gorelick, Sherry. "Contradictions of Feminist Methodology." Gender and Society 5, no. 4 (1991): 460. 
As a result of this goal, I find it of absolute necessity to conduct this research project using a feminist methodological framework. However, as Klein writes, despite the fact that feminist research has flourished in academia, feminist methodology as a topic of its own has not been given much consideration. 61 As a result, I draw upon various strands of feminist writings on methodology to construct my own feminist methodological framework. This framework includes the principle of conscious partiality, the importance of empowering women throughout the research process, the use of the participatory model and the need to consider the role of patriarchal language in the construction of women's experiences. In this chapter I develop these principles and discuss some of their common critiques. I then illustrate my application of these principles to the various stages of my research project, from the formulation of the research project to the data analysis stage.

\section{FEMINIST METHODOLOGICAL PRINCIPLES}

\section{The Principle of Conscious Partiality}

Mies defines conscious partiality as the ability of the researcher to integrate her own subjective experiences of oppression into the research process in order to effectively identify with research participants. 62 The importance of this principle arises from the need to move away from the idea of the value free, neutral and uninvolved approach of traditional methodology, which has been critiqued for promoting an unattainable ideal which masks researcher biases under the guise of "objectivity". Conscious partiality

61 Renate Duelli Klein, "How to do what we want to do: thoughts about feminist methodology" in Theories of Women's Studies, ed. Gloria Bowles and Renate Duelli Klein (London; Boston: Routhledge \& Kegan Paul, 1983), 88-89. 
enables the researcher to develop empathy and a greater understanding of participants' accounts of their own experience. Mies has been critiqued for suggesting that women identify with each other based on their common oppression as women, however Mies can be read as arguing that it is not the identity category in itself which allows women to identify with one another but common experiences that give rise to this identification. I suggest that this understanding of Mies' principle of conscious partiality can be extended beyond shared oppression to encompass other shared experiences, in this case my own suffering with agoraphobia.

There are two additional critiques of the principle of conscious partiality, both of which stem from a concern over the loss of objectivity that results from researcher identification with research participants. The first argues that researcher identification with research subjects results in potential distortion of research data because the researcher interprets participant's experiences through the lens of her own experience and therefore, lacks the objectivity to see these experiences in their own right. The second critique suggests that shared experiences, between the researcher and researched, lead to vulnerability of both during the research process. Griffin, for example, argues that the well-being of the researcher can be compromised when researching "the same" through choice of topic or conduct of research.63 This concern is particularly relevant to this project because a mental disorder is the topic of choice and this elicits concern over the mental well-being of the researcher. The vulnerability of the research subjects is intimately linked with the issue of distortion of research data since the researcher has the 
power to distort the experiences of the women she is researching, which leaves them vulnerable to misrepresentation.

Although these critiques of conscious partiality point to the real potential for bias and increased vulnerability during the research process, they rely on a problematic premise. They suggest that these concerns result primarily from researcher identification with research participants, through shared experiences, during the research process. In reality, the principle of objectivity has been critiqued for a similar problem; the "objective" researcher treats research "objects" as a reflection of his own understanding and experience of the world. In both these cases, the concern is more with a lack of selfawareness of how one's own experiences may impact the research process, an issue of reflexivity rather than an issue of identification. Similarly, the concern with vulnerability of researcher results primarily from a lack of self-awareness of one's mental well-being to conduct the research, and not as a result of a topic that is close to one's heart.

Considering the significance of shared experiences in the development of empathy and understanding, I employ the principle of conscious partiality while taking seriously the critiques that have been raised against it, in particular the concern with a lack of researcher self-awareness. I apply the principle of reflexivity by explicitly taking note of the ways in which my own experiences and beliefs have influenced and shaped various aspects of the research process. This includes my radical feminist beliefs and my own lived experiences with agoraphobia.

\section{Empowering Women During the Research Process}

A common theme, in feminist writings on methodology, is the importance of empowering women throughout the research process. There are two forms of 
empowerment I wish to discuss here. The first is the empowerment of women who participate in the research process while the second is the empowerment of women more broadly. In relation to the first, Devault argues that feminists often attempt to achieve this goal by making visible the experiences and struggles of women.64 However, many researchers have a simplistic response to this directive, assuming that the goal of empowering women can be achieved simply by "giving" women the opportunity to speak about their struggles and experiences. 65 But, as Gorelick describes, ideologies of oppression are often hidden and internalized.66 Therefore, although "giving" voice is a vital first step of empowerment, it is simply not enough. As Gorelick suggests, one must go beyond "giving" voice and employ a process of consciousness-raising (CR) in order to relate the experiences of women to broader structural relations, thus revealing the “internalized" aspect of oppression.67

The second form of empowerment relates to the need for a methodology that supports change to the status of women in society. DeVault suggests that this goal can be accomplished through various means, such as utilizing new theories or producing data that will stimulate or support political action68. Despite the fact that this form of empowerment is often cited by feminist researchers as important to a feminist methodology, there have been few writings on how to assess whether or not a research

64 DeVault, Marjorie L. "Talking Back to Sociology: Distinctive Contributions of Feminist Methodology." Annual Review of Sociology 22, no. 1 (1996): 29-50.

${ }_{65}$ Cancian, Francesca M. "Feminist Science: Methodologies that Challenge Inequality." Gender and Society 6, no. 4 (1992): 623-642.

66 Gorelick, Sherry. "Contradictions of Feminist Methodology." Gender and Society 5, no. 4 (1991): $464-$ 470.

67 Gorelick, "Contradictions of Feminist Methodology", 465-470.

68 DeVault, Marjorie L. "Talking Back to Sociology: Distinctive Contributions of Feminist Methodology." Annual Review of Sociology 22, no. 1 (1996): 30-40. 
project has provided support to a particular political cause or has the potential to stimulate social change. Despite this fact, working towards the goal of supporting social change for women can be considered a vital part of a research project which seeks the empowerment of women in society.

My methodology builds on the feminist suggestions and critiques outlined above to seek the empowerment of both research participants and women more broadly. Since empowering female participants requires more than allowing them to speak about their experiences, because experience is discursively constituted, I employ aspects of the principle of consciousness raising (CR) during the interview process. This allows women to understand the manner in which their oppression is structural, and challenges understandings of their experiences as purely personal struggles. Furthermore, I seek to empower women more broadly through the use of a new theoretical framework which seeks to understand how a woman's agency is constrained through the oppression of her lived body. The use of this framework, to analyze my interview data, seeks to produce research which supports the empowerment of women by highlighting their embodied capacity to resist patriarchal oppression.

\section{Reducing Hierarchy: The Participatory Model}

Feminists often acknowledge that power relations between researcher and research participants are highly unequal, particularly because the researcher has control over the conceptualization and dissemination of the research project and results. This results in the potential of exploitation, misrepresentation and harm to research participants who are vulnerable to being used by the researcher in her own pursuit of "knowledge" claims without any consideration of their well-being. A methodological 
strategy often employed by feminists to destabilize this hierarchy is the use of the participatory model, where research participants are involved in the research process. 69 Their involvement throughout the process, from the conception of the research project to dissemination of research results, is thought to reduce the power imbalance between researcher and research participants.

There are two broad critiques which can be raised in relation to the participatory model, the practicality of involving participants throughout the research process, and the assumption that the researcher is always in a position of power by virtue of her identity as a researcher. The participatory model's suggestion that participants should be involved throughout the research process is impractical because of the reality of completing a research project, particularly at the Master's degree level. First, there are monetary expenses associated with the completion of the project, which are taken on by the researcher. The inclusion of research participants, throughout all stages of the research project, has the potential to greatly extend the amount of time required to complete the project and, as a result, increase the monetary expenses associated with this completion. The second issue with the participatory model, related to the reality of completing a research project, is the structure of a research project. In order to recruit research participants, a researcher must have already conceptualized a research project, to be 
approved by ethics. As such, the inclusion of research participants in the early stages of the research project may not be a possibility.

The second critique, in relation to the participatory model, involves the assumption that the researcher is always in a position of power by virtue of their identity as "researcher". As Cotterill argues, power is a dynamic exchange between researcher and research participants. The assumption that the researcher can "equalize" this power imbalance, through the inclusion of research participants in the research project, is simplistic. I draw upon the participatory model in an attempt to balance the power dynamic in my research project. However, primarily due to monetary and time restrictions in the completion of a Master's degree, I employ it during the interview process rather than throughout the whole research process. Oakley suggests that the application of the participatory model during the interview process should include an investment of the researcher of her own personal identity in the research relationship by answering respondents' questions and sharing knowledge and experience.70 Furthermore, Oakley suggests that responding to participants' emotions, and sharing one's own emotions, is a factor in the cultivation of a less hierarchical relationship.71 I utilize Oakley's suggestions while keeping in mind that my aim to shift power to my 
participants may not always be successful because it may not always be the case that power lies exclusively with me, by virtue of being a researcher.

\section{Patriarchy, Language and Meaning}

Maynard argues that feminist thinking on research has been significantly influenced by postmodernism and its emphasis on language, discourse and representation.72 Feminist theorizing on the role of language in the construction of experience and meaning raises profound epistemological and methodological concerns. In particular, the role of language in mediating how women experience their world has challenged the feminist notion that experience is an unproblematic given that provides direct access to women's lived realities. 73 The new insights that women understand themselves and their experiences through pre-conceived ideas suggest that experience itself is discursively constructed.74 Because of this understanding of the nature of experience, methodological strategies can be employed that aim at the recovery and analysis of experiences that women have difficulty articulating, or may not be fully conscious of.75 Following Devault's suggestion that this strategy should be employed throughout the research process, I consider the role of language in the construction of my

\footnotetext{
72 Renate Duelli Klein, "How to do what we want to do: thoughts about feminist methodology" in Theories of Women's Studies, ed. Gloria Bowles and Renate Duelli Klein (London; Boston: Routhledge \& Kegan Paul, 1983), 90.

73 Mary Maynard, "Feminist Issues in Data Analysis" in Handbook of Data Analysis, ed. Alan Bryman and Melissa A. Hardy (London; Los Angeles, [Calif.] SAGE, 2004), 6-8.

74 Maynard, "Feminist Issues", 8.

75 Devault, Marjorie L. "Talking and Listening from Women's Standpoint: Feminist Strategies for Interviewing and Analysis." Social Problems 37, no. 1 (1990): 96-97.
} 
topic, in the approach I use for interviewing participants and during the transcription process.

\section{APPLYING FEMINIST PRINCPLES TO THE RESEARCH PROCESS}

\section{Formulating the Research Project: My Lived Experiences as a Starting Point}

The original idea for this research project developed at the beginning of my

Master's degree, as I began to apply various theoretical frameworks to my personal life, in particular radical feminism and feminist phenomenology. My application of radical feminism to my life led to an increased awareness of the political nature of my seemingly personal issues, like my heterosexual identity. This awareness drove my desire to understand how other seemingly "personal" issues, such as "mental illness", might also be political issues. In particular, I was interested in another personal issue I had encountered through most of my life, my experience with the "mental disorder" of agoraphobia. My desire to understand agoraphobia, from an embodied approach, was driven largely by my application of feminist phenomenology to an understanding of my own lived oppression. This led me to an appreciation of how my daily embodied experiences were shaped by heteronormative standards of behavior and that my agential capacities to resist these norms lay in enacting daily bodily forms of resistance. Thus, my feelings of empowerment which resulted from this process were important in formulating a research project which sought to empower other women through the use of a feminist phenomenological theoretical framework.

It is important to consider a limitation of employing this method in my study of other women's lived experiences with agoraphobia. My experience of the world is highly influenced by aspects of my identity, as a woman and as a lesbian. As a result, the 
empowerment I felt from the use of radical feminism, and my subsequent theorization of the role of women's oppression in the development of agoraphobia, are directly related to these identity markers which characterize the radical feminist thought I utilize. Since different women identify in different ways, the things they experience, and the experiences that are most relevant to their lives, will differ. As a result, the use of radical feminist theory to understand the development of agoraphobia will exclude other aspects of identity that may be relevant to women's development of agoraphobia. Understanding this limitation provided the impetus to apply a phenomenological methodology which required me to ask questions about the lived bodily experiences of the women I interviewed. Asking these types of questions provides me with the knowledge of how other women perceive their experiences, which lessens the potential to conflate my own experiences with theirs.

Furthermore, because the purpose of my research project is to challenge current conceptualizations of agoraphobia, and because meaning and experience ares discursively constructed, my understanding of what my usage of the term "agoraphobia" refers to had to be critically analyzed before embarking upon the research project. I began the project seeking to study "agoraphobia", and quickly became uncomfortable with the term because its construction relied upon problematic understandings of individual women who suffered from the "disorder". For example, it implied, through the label mental disorder, that individual agoraphobic women were defective, that the "problem" lay within them rather than in broader society. Since women constitute about 80 percent of agoraphobics, and live in a patriarchal society, I found this implication suspect. As a result of this reflection, I define agoraphobia as the lived experiences of reoccurring panic 
attacks and avoidance behaviors that have come to be classified as a "mental disorder". This allows for a definition of agoraphobia according to how individual women actually experience it rather than according to its construction as a "mental disorder".

\section{Recruiting Agoraphobic Women for The Research Project}

I sought to recruit female born women who had been diagnosed with agoraphobia for a minimum of two years. The radical feminist framework I employed argues that the oppression of women is not solely a result of gender identification, but also of the biological differences between the sexes. Women are oppressed by virtue of their socialization into gender roles which arise from the perception that their biology is different from, and inferior to, a man's. The reason for recruiting female born women is that most agoraphobics are female born women, and this research project seeks to understand whether aspects of their socialization into a "female" identity played a role in the development of agoraphobia. The decision to recruit women who have been diagnosed with agoraphobia for a minimum of two years was made in order to minimize the potential of psychological harm to participants on the assumption that a diagnosis meant that they had sought professional help.

I began the recruitment phase under the problematic assumption that my feminist methodological principles were not particularly relevant for the recruitment stage and that standard practice for recruitment would be sufficient to recruit the necessary number of research participants, about 10-15 women. Standard practice included the use of recruitment posters, which were posted on university campuses, social media sites, and various therapists' offices, as well as snowballing. Third parties were required in the recruitment of participants from therapists' offices because I had to give my posters to the 
therapists in order to have them posted. However, these strategies resulted in minimal recruitment of participants which highlighted the importance of feminist methodological principles at this stage.

The two feminist methodological principles that became important in recruiting the necessary number of participants are the principle of conscious partiality and the participatory model. In relation to the former, upon self-reflection I realized that I had devalued my experience with agoraphobia in the recruitment stage because I believed that standard methods were superior to my own ideas about recruitment. Upon failing to recruit participants with these methods, I drew upon my wealth of personal knowledge of living with agoraphobia to determine that part of the reason why recruitment was not successful might be because of the intense fear associated with agoraphobia, which kept agoraphobic women from either being in spaces where the posters were posted, or from wanting to initiate contact with a stranger.

As a result of this reflection on my recruitment strategy, I decided to recruit primarily through social media in an informal fashion. The use of social media platforms for recruitment allowed me to address the lack of agoraphobic women in public spaces and allowed me to initiate contact with them, which reduced the fear of contacting a stranger. Through my initial contact, I was able to introduce myself in an informal manner as someone who was also suffering from agoraphobia and who was conducting research on the topic. I initially began an informal conversation with participants and was able to address fears they might have in regard to participation. This modified approach reduced the hierarchical nature of recruitment by allowing potential participants to have more say in how the research would be conducted. For example, if they were initially 
worried about a skype interview because they did not want to appear on camera, I informed them that the camera was not necessary for the interview process. Through this process I quickly recruited 10 participants for my research project.

\section{Data Collection}

The method of data collection that I used for my research project is a feminist phenomenological interview. Although my initial desire to conduct face-to-face interviews was driven by best practice for interviewing, the difficulty of arranging in person interviews with agoraphobic women drove the need to conduct skype interviews. The majority of agoraphobic women who lived in Ottawa, and contacted me to attend an in-person interview, either did not show up at the chosen location or cancelled the interview. Since I did not hear back from many of them, I suggest that their condition made it difficult for them to attend in-person interviews. Agoraphobia tends to severely restrict an individual's capacity to move around freely and independently because of debilitating panic attacks.

As a result of the difficulty in scheduling in-person interviews, I decided to conduct skype interviews with all my participants. Deaken et al argue that the quality of responses gained through online research can be much the same as traditional methods of interviewing, and allow for greater flexibility.76 In addition to allowing greater flexibility in the scheduling of interviews, skype was particularly useful for conducting interviews with agoraphobic women because it did not require them to leave the home to attend the interview. Since most of the agoraphobic women I conducted interviews with did find it

\footnotetext{
76 Deakin, Hannah and Kelly Wakefield. "Skype Interviewing: Reflections of Two PhD Researchers." Qualitative Research 14, no. 5 (2014): 603-610.
} 
difficult to leave their homes, this greatly facilitated their ability to participate. Skype facilitated the application of the participatory model, which had a significant impact on participation by allowing agoraphobic women to exercise greater control over the interview process. Furthermore, skype allows participants to choose whether they are comfortable with audio or video interviewing, to terminate the interview whenever they feel uncomfortable and to control the environment around them during the interview.

My interview questions were developed with the desire to understand whether there were commonalities in the life experiences of women who suffer with agoraphobia, in particular prior to their development of the "disorder". The focus of the questions was on experiences with anxiety and fear during early childhood and adolescence. Furthermore, because I sought to understand women's embodied experiences during these time periods, a phenomenological approach to developing interview questions was utilized. This approach focuses on developing questions that seek to elicit accounts of women's perception of the events that occur, rather than a focus on the events themselves. This focus on perception is important in light of the fact that agoraphobia develops from a perception of the world as an inherently dangerous place, despite the fact that most panic attacks that agoraphobic women experience do not occur as a result of "objectively" fear inducing events.

I developed interview questions with the principle of reflexivity in mind.

Practically, this meant that I formulated questions that were as broad and open-ended as possible so that my data would not be distorted by confirmation bias. By not directly asking questions of interest to me, women could articulate the experiences that were most important to them and in this way had more control during the interview process. Control 
was also shifted towards the participants by my perception of the questions as guidelines rather than a strict question/answer format. Practically, this meant that there was not consistency across interviews in regard to the specific questions asked. However, because I did not seek answers about particular events, but rather stories about life experiences, lack of consistency did not pose a problem as long as questions remained of a similar type across interviews.

\section{The Feminist Interview}

Feminist interviewing principles were utilized throughout the interview process, such as the cultivation of a less hierarchical research encounter, the use of consciousnessraising, reflexivity and attention to patriarchal language. Following Oakley's suggestions for cultivating a less hierarchical research relationship77, I informed each participant at the beginning of the interview that the interview is meant to be informal and that they could ask me questions if they wanted to. I invested my own personal identity by sharing how I suffered with agoraphobia while sharing some of my childhood experiences with anxiety, particularly when they allowed me to identify with participants. I stopped the interview when emotions were being expressed in order to address them, and I shared my emotions freely and openly with participants.

My application of these methods seemed to be successful in creating a less hierarchical research relationship. Participants asked me questions about my agoraphobia, if I had any advice on how to conquer it, as well as questions related to other aspects of my personal life. I found that sharing my own experiences allowed for the development

77 Campbell, Rebecca, Adrienne E. Adams, Sharon M. Wasco, Courtney E. Ahrens, and Tracy Sefl. "'What has it been Like for You to Talk with Me Today?": The Impact of Participating in Interview Research on Rape Survivors." Violence Against Women 16, no. 1 (2010): 62-63. 
of a sense of closeness during the interview process. This can be more clearly seen from the fact that the majority of the participants asked if they could be Facebook friends with me or if we could keep in touch. Most participants expressed that, despite feeling apprehensive about being interviewed, they found the interview process to be therapeutic and highly enjoyable. Although this method was useful for reducing the hierarchical nature of the interview setting, in one case it resulted in a problematic shift in power. For example, one participant often deflected questions directed towards her by asking questions herself, particularly questions of a personal nature. This could have resulted from a failure of the application of the method or an unwillingness on the part of the participant in sharing certain details of her life.

A potential problem that could arise as a result of this form of "closeness" that is cultivated, is the reliance of participants on the researcher as a friend after the completion of the research process. Since the participants asked me if I could be their Facebook friend, it may present an issue for me, as the researcher, in providing additional support for the participants after the completion of the research project. Aside from placing a potential burden on me, it could also result in misleading participants into thinking that a genuine friendship has been formed. In relation to the former, I provide a list of resources for participants upon the completion of the interview, and I let them know that I am not a counsellor or able to provide any support in that capacity. The friendship issue relies on a problematic assumption that a genuine friendship cannot be formed from a research encounter because the researcher merely requires the research participants for her study. 
The decision to become friends should be on an individual basis, depending on the desire of the participant and of the researcher.

The second feminist principle I employed for my interviews with agoraphobic women is the principle of consciousness-raising (CR). Although I began each interview with the intent of empowering women in this manner, I found it highly impractical and nearly impossible to facilitate CR during an interview. There are two main reasons why this was the case, the fact that CR should be a voluntary decision to engage with structural causes of common experiences, and the nature of the interview setting. Original CR groups were collaborative and required that all parties be interested and willing to understand their experiences through a broader structural lens. My attempts at facilitating a form of collaborative engagement with broader patriarchal structures failed primarily because my participants did not attend the interview with the desire to participate in CR. However, even if it was the case that participants expressed a genuine interest in CR during the interview process, the interview setting is not particularly conducive for CR because of the hierarchical nature of this setting. My best attempts at reducing hierarchy within the interview setting, through a participatory approach, still results in a power differential which would undermine the collaborative process of CR. As a result, $\mathrm{CR}$ as a principle of empowerment is not suitable for the interview process.

As Devault argues, feminist researchers need to consider the role of language when interviewing women because patriarchal concepts often obscure the reality of women's experiences.78 When conducting my interviews, I took this into consideration

78 Devault, Marjorie L. "Talking and Listening from Women's Standpoint: Feminist Strategies for Interviewing and Analysis." Social Problems 37, no. 1 (1990): 96-105. 
by listening for incompletely articulated aspects of women's experiences and working with them to better articulate how they were feeling and what they were experiencing. My ability to apply this principle consistently was challenged by the reality of the interview process. First, although I was able to listen for ambiguity and problems of expression, the time constraints made it difficult to develop more complete accounts of experience. For example, probing into the nature of an experience may lead the interview process astray, and result in a detailed account of an experience that may not necessarily be relevant to the research project. Furthermore, ethical concerns arise in relation to attempting to recover experiences that are incompletely articulated. For example, they may be incompletely articulated because of emotional trauma or abuse, and, as a result, their unveiling may cause harm to the participants.

As a result of the above, the importance of considering language when interviewing women is a relevant principle to apply but should be applied with caution. First, the relevance of the experience to the research project should be taken into consideration; will the attempt to elicit a more complete articulation contribute to an understanding of the topic being investigated? If it will, an argument can be made for the relevance of probing. If it will not, it can be argued that it may not significantly contribute to an understanding of the topic while simultaneously potentially harming the participant. Secondly, considering the potential for participant harm, any probing should 
be done with a licensed therapist present in order to ensure that any emotional traumas are dealt with in an effective manner.

\section{The "Data Analysis" Stage}

Maynard argues that there has been very little feminist concern with the data analysis stage of the research project. 79 She suggests that this is primarily a result of the fact that feminist work is highly critical of standardization. There has been a recent push within social science research toward the creation of highly structured and systematic procedures for data analysis in response to claims that qualitative research is unscientific. Another reason why there tends to be very little discussion of data analysis is because feminist research tends to view the approach to analysis through the lens of the research project design, which means that the data analysis stage will vary significantly depending on the theory employed and the goals of the research project.

Given the lack of feminist writing on data analysis, this research project employs a feminist approach to a traditional mode of analysis in psychology, Braun and Clarke's thematic analysis. 80 Braun and Clarke were the first to clearly outline the theory, application and evaluation of thematic analysis in an accessible manner. They provide a step-by-step guide to conducting a thematic analysis in a deliberate and rigorous way. The steps are familiarization with the data, generating initial codes, searching for themes, reviewing themes and defining and naming themes. 81 Since this form of thematic analysis offers an accessible and theoretically flexible approach to analyzing qualitative data, I

79 Mary Maynard, "Feminist Issues in Data Analysis" in Handbook of Data Analysis, ed. Alan Bryman and Melissa A. Hardy (London; Los Angeles, [Calif.] SAGE, 2004), 6-15.

80 Braun, Virginia and Victoria Clarke. "Using Thematic Analysis in Psychology." Qualitative Research in Psychology 3, no. 2 (2006): 77-101.

81 Braun and Clark, "Using Thematic Analysis", 86-87. 
apply a feminist theoretical framework to it. Practically speaking, for my work this meant conducting data analysis while taking into account the importance of empowering women and accounting for the principle of reflexivity.

The first step in my data analysis involved immersing myself within the research data through repeated readings. I then transcribed the interview data in a manner which reflected the emotional, contextual and specific linguistic elements of the interview. Three dots were used to indicate any missing dialogue, two dashes to indicate a long pause, one dash to indicate a short pause, underlining to indicate emphasis on words, and brackets to record the display of emotions. I noted all casual and formal conversation, as well as when there was an interruption and how it was dealt with. This form of transcription was important for ensuring that the data transcript accurately reflected the experiences agoraphobic women spoke to and any difficulties in articulating these experiences.

After transcription of the interview data, I began the process of generating initial codes, which refers to the most basic segment of the raw data that can be assessed in meaningful ways. Braun and Clarke suggest that coding depends on whether your thematic analysis is theory driven or data driven. 82 Despite the fact that my analysis is driven by feminist theory, I nevertheless coded for all potential themes following a data driven approach. For my research project, a data driven approach is in greater accordance with the principle of reflexivity because my theoretical framework has been developed from my own personal experiences. As a result, by reading the data through a theory

82 Braun, Virginia and Victoria Clarke. "Using Thematic Analysis in Psychology." Qualitative Research in Psychology 3, no. 2 (2006): 83.s 
driven approach, there is a greater risk in understanding participants experiences primarily through the lens of my own experiences. Although a data driven approach is never completely free from this risk, it allows for a greater potential to reflect on how my own experiences inform which aspects of the data I focus on by not eliminating data which does not already conform to my experiences.

Finally, using the coded data I identified themes throughout the data set. I determined a theme was prevalent when it occurred in the majority of the interviews, at least eight or nine of the ten I conducted. I conducted what Braun and Clarke refer to as an inductive thematic analysis. I searched for themes without trying to fit coded data into my pre-existing analytical framework of feminist phenomenology. However, since it is practically impossible for a researcher to free herself of her theoretical commitments, I found myself searching for themes that centered around a feminist phenomenological analysis. At this stage, I also created a "miscellaneous" section to house codes that didn't fit into main themes.

Upon my identification of twelve "potential" themes, I reviewed the data extracts within each theme to ensure that they cohered together meaningfully. Finally, I defined and named the themes. At this step, I also determined which themes to keep and which to discard for my analysis. My decision revolved around both the amenability of themes to my theoretical framework as well as, what I labelled, the "strength" of the theme; whether the coded data within the chosen theme really captured the essence of the theme itself. I initially identified four main themes for interpretive analysis, however, this was narrowed down to three because one theme was found not to have substantive coded data. Outliers and "lesser" themes were kept for discussion in the conclusion of the research 
paper in order to highlight the need for further exploration into an understanding on the development of agoraphobia and to discuss some of the limitations of a thematic analysis.

\section{RADICAL FEMINIST PHENOMENOLOGY: A THEORETICAL}

\section{DEVELOPMENT}

The choice of which theoretical framework to employ for a particular research project can be complex because different theories present different understandings of the topic under investigation. As a result, the choice of theory will depend significantly on the researcher and the researcher's inclinations. In regard to this research project, I develop a radical feminist phenomenology because of my desire to work with a theory which could account for the high rates of agoraphobia in women (radical feminism), as well as my desire to discuss agoraphobic women as agents of their oppressive circumstances through a discussion on the lived body (phenomenology). In order to "develop" this theory, I draw on Hoagland's radical feminist ideology of protection and predation and I apply this framework to Young's feminist phenomenological theory. In doing so, I modify Young's feminist understanding on how women experience their bodies in a patriarchal society. Although this framework is developed to describe the lived bodily experiences of women, through its development I describe how these lived bodily experiences are constituted. It is this description, of the socialization into what I coin "female bodily existence", that I ultimately employ for an understanding of the topic under consideration.

This chapter proceeds as follows: I discuss radical feminist theory more broadly, outlining its central tenets, and then I proceed to discuss the specific radical feminist theory that I utilize for this research project, Sarah Hoagland's theory of protection and 
predation. Following this discussion, I proceed to outline some general critiques of radical feminist theory, which have attempted to relegate radical feminism to a "no longer relevant" past. After review of these critiques, I assert the importance and relevance of Hoagland's radical feminism to a study of agoraphobia. Following this discussion of radical feminist theory, I outline Young's feminist phenomenology and discuss the relevance of a phenomenological approach to an understanding of agoraphobia. Finally, I modify Young's feminist phenomenology to develop a radical feminist phenomenological approach. As discussed above, this framework allows for a radical feminist understanding of female bodily existence as well as an understanding on how the lived body is socialized into female bodily existence.

\section{A REVOLUTIONARY IMPULSE: RADICAL FEMINIST THEORY}

"A peculiar problem arises when stories of social change - and the radical figures of those stories - persistently stay in the past tense." - Ti-Grace Atkinson

The various strands of radical feminist thought can be characterized by skepticism of change within the current political system and a revolutionary approach to the dismantling of patriarchal political and social institutions. Radical feminists claim the necessity of women's liberation, which stands in stark contrast to claims by liberal feminists for the equality of women with men. A central tenet of radical feminism is that women require liberation from male domination because society is organized around the principle of male domination. 83 Although liberal feminists similarly believe that men dominate political and social institutions, they differ in the fact that they believe inclusion

83 Catharine A. MacKinnon, "Sexuality, Pornography and Method: Pleasure Under Patriarchy" in Feminism and Philosophy: Essential Readings in Theory, Reinterpretation, and Application, ed Nancy Tuana and Rosemarie Tong (Boulder, Colo: Westview Press, 1995) 134. 
of women within these institutions is what is necessary to achieve women's freedom. 84 Radical feminists argue that male domination of women does not originate within these institutions and, as a result, inclusion is not sufficient. According to radical feminism, male domination runs deeper than political institutions; it fundamentally structures the meaning of the term "woman" and, as a result, is an ontological oppression.

An important distinction to make at this point is that radical feminists believe that the oppression of women is a sex-based oppression. Thus, there is an implicit understanding of the term "woman" as referring to a human female. This means that male domination structures the understanding of a female being as a "woman", and this includes the socially constructed nature of gender and sexuality.85 Both gender and sexuality are constructed in such a manner as to ensure male domination of the female sex. Gender ensures that this domination maintains itself by naturalizing a sense of female submission. 86 This naturalization ensures that the female being perceives her state of oppression to be as "nature intended it", based on her biological functions. According to radical feminists, this is central to ensuring that women do not rebel against their oppression; they perceive it as simply part of who they are. Sexuality, on the other hand, eroticizes male domination. As such, the female sexual drive is structured around the desire to be dominated, the desire to be submissive; ultimately, the desire to be

84 Melissa A. Butler, "Early Liberal Roots of Feminist: John Locke and the Attack on Patriarchy" in Feminism and Philosophy: Essential Readings in Theory, Reinterpretation, and Application, ed Nancy Tuana and Rosemarie Tong (Boulder, Colo: Westview Press, 1995) 10-15.

85 Fahs, Breanne. "Ti-Grace Atkinson and the Legacy of Radical Feminism." Feminist Studies 37, no. 3 (2011): 561-590. 
oppressed. 87 By constructing an understanding of "woman" as a female being which is by her nature submissive, and who sexually and romantically desires this submissiveness, a female being's sense of self is dominated by these understandings.

As a result of the radical feminist belief that gender and sexuality are social constructs, which work in cohesion to oppress women (read: females), radical feminists seek to analyze the principal sites and institutions that work to construct women's gender and sexuality. For example, Adrienne Rich examines the institution of heterosexuality, arguing that heterosexuality is far from an "innate orientation" or preference. 88 Instead, she argues that the institution of heterosexuality ensures that heterosexuality is compulsory and outlines eight characteristics of male power which work to enforce heterosexuality as inevitable and natural to women. These include the power of men to deny women their own sexualities, to exploit their labour, and to confine them physically and prevent their movements etc. 89 As a result of the compulsory nature of heterosexuality, "women actively participate in the colonization of themselves through male identification".90 Radical feminists have analyzed pornography as another site of the social construction of gender and sexuality. In particular, both MacKinnon and Dworkin argue that pornography constructs sexuality as the forcible violation of women. In "Toward a Feminist Theory of the State",91 MacKinnon argues that sexuality is defined

\footnotetext{
87 Rich, Adrienne and Leila J. Rupp. "Reflections on 'Compulsory Heterosexuality'." Journal of Women's History 16, no. 1 (2004): 8.

88 Rich, Adrienne Cecile. "Compulsory Heterosexuality and Lesbian Existence (1980)." Journal of Women's History 15, no. 3 (2003): 11-15.

89 Rich, Compulsory Heterosexuality, 18-20.

90 Rich, Compulsory Heterosexuality, 25.

91 MacKinnon, Catharine A. Toward a Feminist Theory of the State. Cambridge, Mass: Harvard University Press, 1989.
} 
through violence where "female sexuality" is defined by what male desire requires for arousal and satisfaction. She suggests that a feminist theory of sexuality locates sexuality within a theory of gender inequality such that it treats sexuality as a social construct of male power, constitutive of the meaning of gender.

\section{Heterosexualism and the Ideology of Protection and Predation}

The particular radical feminist theoretical framework that will be drawn upon for the purposes of this research project will be Sarah Hoagland's understanding of the ideology that sustains heterosexualism. Hoagland coins the term "heterosexualism" to describe a particular economic, political and emotional relationship between men and women, where men must dominate women and women must subordinate themselves to men in a number of different ways. 92 She suggests that it is an entire way of living that normalizes the dominance of one person in a relationship and the subordination of the other. Her intent in coining the term "heterosexualism" was to challenge the limited nature of liberal resistance to lesbian and gay oppression which she perceives as largely an effort at assimilation and acceptance of the dominant logic of heterosexual society.

According to Hoagland, heterosexualism manifests through an ideological framework of protection and predation. 93 Men gain their identities by taking on the roles of predators or protectors whereas women gain their identities by taking on the role of victim in need of "protection" from "predators". Male predators' and protectors' interactions with women define women as helpless, in danger, as perpetual victims. Men

92 Sarah Lucia Hoagland, "Moral Revolution: From Antagonism to Cooperation" in Feminism and Philosophy: Essential Readings in Theory, Reinterpretation, and Application, ed Nancy Tuana and Rosemarie Tong (Boulder, Colo: Westview Press, 1995) 175-176.

93 Sarah Lucia Hoagland, Moral Revolution, 176. 
who take on the role as a predator define women as in danger of male sexual and physical violation through raping, physically violating and sexually objectifying women. On the other hand, men who take on the role of a "protector" define women as in danger through promoting the image of women as vulnerable to predatory attacks by other men. 94 Because this ideology naturalizes a relationship of dominance and subordination between men and women, men are taken to be "natural" predators and protectors. As a result, they interact with women as beings that, by their nature, attract male sexual predation. Hoagland argues that this can most clearly be seen in the case of rape, where the argument is presented that a woman entices a man to rape her by her appearance or her actions. 95

Because of the logic of this ideology of male domination, a woman's integrity and agency are undermined. "Protectors" undermine her agency through intervening in her affairs "for her own good" whereas "predators" accomplish this goal by directly violating and humiliating women through rape and violence.96 Furthermore, since this ideology naturalizes a relationship of heterosexualism, women are actively involved in maintaining this relationship. Women take on roles as "prey" in need of protection and interact with men in ways that define men as their "protectors" and "predators". They actively seek out male "protectors" in order to ensure that they remain safe from predatory male.

94 Sarah Lucia Hoagland, Moral Revolution, 176-180.

95 Ibid., 179.

96 Ibid. 
Furthermore, they actively sexually objectify themselves, making themselves vulnerable to predatory attacks because they are, by their "nature", sexually attractive.97

\section{The Oppression of Women - Which "Women"?}

Radical feminist theory presents a powerful and fundamental understanding of the source of women's oppression through an analysis of patriarchal institutions. Not surprisingly, an indictment of all of society's structures and institutions as fundamentally patriarchal does not stand without some serious critique. Unlike critiques that have been raised in relation to other feminist theoretical frameworks, the critiques of radical feminist theory have significantly contributed to the decline of the perceived relevance of this theory, both academically and politically. The theory has been relegated to a "not so relevant" past and considered to be superseded by "superior" feminist theoretical frameworks which remedy the perceived shortcomings of radical feminism. I will address a few common critiques in this section. First, critics of radical feminist theory often suggest that it is essentialist, meaning that it assumes that there is some essential, innate quality that all women share such that their oppression can be meaningfully spoken about as "women's" oppression. A second critique I will consider is the claim that radical feminism lacks a consideration of intersectionality. Finally, I will address the critique that radical feminist theory primarily represents women as passive victims of the patriarchy.

When critics raise the argument that radical feminist theory is essentialist, they tend to make reference to two ideas of what it means to be essentialist. First, there is the claim that radical feminist thinking is essentialist because it locates the source of

97 Ibid., 180-185. 
women's subordination in female biology. This form of essentialism is often labelled as biological determinism. That is, radical feminists are critiqued for supposedly suggesting that all women share biologically determined traits which are the source of their subordination by men. The second form of essentialism that radical feminists are accused of is gender essentialism. Critics suggest that radical feminists are gender essentialists because they assume that women share some innate behavioral characteristics when they suggest that all women are oppressed as women. This critique differs from the critique that radical feminists are biological determinists in that it does not accuse them of suggesting that these "innate" traits are necessarily biological.

The first claim fundamentally misreads one of the main premises of radical feminist theory, the idea that the current perception of women as naturally and biologically inferior is a social construct. According to radical feminism, it is through the social construction of femininity, which is imposed onto the female body, that the perception of biological inferiority is maintained by naturalizing certain behaviors and ways of being for the female person. Thus, it is simply incorrect to argue that radical feminists are biological determinists. The perception that this is the case most likely arises as a result of the conflation of Firestone's "Dialectic of Sex" with all of radical feminist thought. In the Dialectic of Sex, Firestone argues that it is because of women's biological inferiority (read: their reproductive capacities) that they are oppressed.98 Thus, she necessarily suggests that there are certain gendered "roles" that arise as a result of women's reproductive capacities and that men exploit these roles. However, her thought 
is not representative of the majority of radical feminist thought which argues that this perception of biological inferiority is socially constructed.

The second critique, that radical feminists are gender essentialists, has been raised both within and outside of feminist circles. A driving force behind this claim is the postmodernist assertion that gender is a social construct and, as such, when radical feminists make reference to "women's" oppression they are suggesting that women share some innate, essential characteristics that make them "women". The argument goes that if gender has been socially constructed, then the term "woman" is referring to a sort of nonexistent entity; no "woman" actually embodies the socially constructed characteristics associated with the term. As a result, when radical feminists discuss women's oppression they are assuming that all women embody these characteristics similarly, which suggests that they are "natural" to women. However, to claim that because gender is a social construct, any reference to women's oppression is essentialist, is problematic because it assumes a radical dichotomization between the socially constructed and the "real". According to this argument, the embodied must be innate whereas the socially constructed is merely in the realm of ideas. However, it can be the case that the socially constructed is embodied similarly because they endure the same socialization process and, as such, the embodied characteristics of an individual need not arise only as part of their "innate" nature.

A related critique of radical feminist thought is that it lacks a consideration of intersectionality. It is often other feminists who claim that radical feminist thought tends to ignore differences amongst women because it claims that patriarchal oppression is the primary driving force behind women's oppression. Intersectional feminists claim that this 
obscures the importance of race, class and culture in women's lives and how these factors intersect to impact different women's experiences of oppression. Yet, to claim that patriarchal oppression is primary to women as a group does not, in itself, foreclose the possibility for discussion on the ways in which patriarchal oppression colludes with other forms of oppression, such as racial oppression, to maintain the oppression of women. In fact, radical feminists' discussion around how patriarchy oppresses women is fundamentally intersectional in that it considers how the social construction of sexuality and gender maintain male dominance over women. A discussion of patriarchal oppression as primary to women as a group does not foreclose the potential to consider the ways in which differently situated women may experience racial oppression as primary at different points in their life.

A further critique of radical feminism is that it is anti-sex and represents all women as passive victims of aggressive males. This critique is fundamentally an attempt to discredit radical feminist arguments without engaging with the content of the argument itself. For example, the fact that radical feminist theory problematizes the conceptions of desire and pleasure that are currently aspects of the social construction of sexuality does not imply that the theory is against pleasure or "sex". The only way in which this implication could be accurate is if our current conceptions of sex and pleasure are the only possible conceptions, which would imply that sexuality is not really socially constructed at all. Furthermore, the argument that radical feminism represents all women as passive victims without agency is problematic because the whole purpose behind radical feminist consciousness raising groups was for women to become aware of their victimization in order to assert their own agency and revolt against patriarchy. The pull of 
such a critique lies less in actual problems with radical feminist thought and more in the patriarchal conceptualization of the dichotomy between victim and perpetrator, which makes it difficult to understand how the knowledge of victimization can be agency inducing.

\section{The Relevance of Hoagland's Theory to the Study of Agoraphobia}

In light of the above critiques, radical feminist theory continues to remain relevant because of its foundational analysis of the pervasive and insidious nature of male dominance within all of society's institutions and structures. In particular, I suggest that Hoagland's theoretical framework of protection and predation is relevant to a study on the nature of agoraphobia for two reasons. The first reason is that it explains how women are socialized to experience themselves as naturally vulnerable to male predation. Since a central experience of agoraphobia is panic attacks, which the agoraphobic woman experiences as if her life is in imminent danger, the lived experience of agoraphobia is one which is characterized by the constant feeling that one's life is in danger. I want to explore the potential role that the socialization process outlined by Hoagland might play in agoraphobic women's experiences of themselves as constantly in danger since this process suggests that they are socialized to experience themselves as in danger.

The second reason that this theory is relevant to a study of agoraphobia is that it explains how women are socialized to seek out "protection" from potential predatory attacks by seeking a "protector", by remaining within the home, or by appearing "feminine". Hoagland argues that women are socialized to seek this protection because by seeking out this protection they experience a sense of "safety" from their experience 
of themselves as constantly potentially vulnerable.99 I suggest that this aspect of women's patriarchal socialization may play a role in the agoraphobic experience of seeking safety from panic attacks. As stated in the DSM-5, agoraphobic individuals tend to feel safer and tend to experience less panic attacks when they are with their "safe person" or when they are within the vicinity of their safe "space". 100 The safe space is usually the home, though it has the tendency to be associated with where the "safe person" may be found. Hoagland's argument on how women are socialized to experience themselves as safe from predators may potentially shed light on why agoraphobic women experience themselves as safe from panic attacks in the particular manner that they do.

\section{FEMINIST PHENOMENOLOGY: ON WOMEN'S LIVED BODILY}

\section{EXPERIENCES.}

“One is not born, but rather becomes, a woman." - Simone de Beauvoir

Radical feminist theory provides an analysis of broad ideological and institutional systems of patriarchal oppression. The particular radical feminist framework that Hoagland outlines provides an understanding of the manner in which females are socially constructed to exist in a patriarchal society. This theory was chosen for its potential to illuminate aspects of women's experience with agoraphobia. However, because the focus of all radical feminist theory is on broad structures of patriarchal oppression, and how they work to oppress women, this theory does not address the lived embodied

99 Sarah Lucia Hoagland, "Moral Revolution: From Antagonism to Cooperation" in Feminism and Philosophy: Essential Readings in Theory, Reinterpretation, and Application, ed Nancy Tuana and Rosemarie Tong (Boulder, Colo: Westview Press, 1995) 175-180.

100 Cornacchio, Danielle, Tommy Chou, Hayley Sacks, Donna Pincus, and Jonathan Comer. 2015. clinical consequences of the revised dsm-5 definition of agoraphobia in treatment-seeking anxious youth.

Depression and Anxiety 32 (7): 502-6. 
experiences of women in a patriarchal society. In order to account for these experiences, I have adopted a phenomenological approach to the application of Hoagland's theory looking for a fuller understanding of agoraphobic lived experiences. In particular, such an approach allows for the potential consideration of agoraphobic lived experiences as products of a process of patriarchal socialization of the embodied self.

\section{From Merleau-Ponty to Iris Marion Young: Developing a Feminist Phenomenology}

Phenomenology is primarily concerned with the study of consciousness and the objects of direct experience. Phenomenologists who wrote prior to Merleau-Ponty argued that reality consists of objects and events (known as phenomena) as they are perceived or experienced in human consciousness. 101 In studying the constitution of reality through the perception of phenomena in human consciousness, these philosophers advanced the argument that subjectivity is located within human consciousness; a subject is capable of intentional action in the world because of her ability to have lived experiences which are directed towards various phenomena according to her intentions. Merleau-Ponty reorients the entire tradition of locating subjectivity within consciousness by locating it within the body.102 Thus, for Merleau-Ponty, there is world for a subject only insofar as the body has capacities by which it can approach, grasp and appropriate its surroundings in the direction of its intentions. The primary distinction between earlier phenomenologists and Merleau-Ponty lies in the locus of subjectivity.

Iris Marion Young combines an understanding of the conceptualization of subjectivity by Merleau-Ponty with Simone De Beauvoir's account of women's existence

101 Young, Iris Marion, 1949 and ProQuest (Firm). 2005. On Female Body Experience: "Throwing Like a Girl" and Other Essays. New York: Oxford University Press, 35-36.

102 Young, Iris Marion, Throwing Like a Girl, 35. 
in a patriarchal society in order to develop a theory which accounts for the lived embodied experiences of women within contemporary patriarchal society. De Beauvoir employs the terminology of existential philosophy to argue that a woman's existence in a patriarchal society is defined by a basic tension between immanence (object-status) and transcendence (subjectivity). ${ }_{103}$ She argues that the culture and society within which women dwell defines her as the "other", as mere object and immanence. Because of this existential structuring, woman is denied the subjectivity which is definitive of being human and which is accorded solely to man.104 Patriarchal society accomplishes this existential oppression of women through many means, primarily through the imperative of normative femininity. Yet, despite the fact that patriarchal society traps women in a state of immanence, De Beauvoir argues that "the female person necessarily is a subjectivity and transcendence and knows herself to be" because she is a human being. 105 According to De Beauvoir, this contradictory existence is what defines the feminine being. De Beauvoir makes it clear that all human beings are always both immanent and transcendent beings; the difference in the account of women's existence is that they are trapped in a state of immanence.

Young combines these insights of De Beauvoir's development of feminine existence, with Merleau-Ponty's understanding of embodied subjectivity, in order to develop an account of feminine embodied existence in a patriarchal society. She suggests that feminine embodied existence exhibits three modalities of feminine motility, two of

103 Young, Iris Marion, Throwing Like a Girl, 29.

104 Young, Iris Marion, Throwing Like a Girl, 31-32

105 Young, Iris Marion, 1949 and ProQuest (Firm). 2005. On Female Body Experience: "Throwing Like a

Girl" and Other Essays. New York: Oxford University Press, 31. 
which I review here,s an ambiguous transcendence and an inhibited intentionality.106 The third one is left out primarily due to time constraints in the completion of the analysis section of this thesis. The idea of feminine embodied existence as an ambiguous transcendence draws upon the understanding of transcendence, here understood as agency, in Merleau-Ponty's (M-P) account of embodied subjectivity.107 M-P argues that transcendence can only occur for a subject when a subject has a body that can act within the world in relation to that subject's intentions. However, drawing on De Beauvoir, Young argues that since women are conditioned by patriarchal society to experience themselves as objects in the world, the experience of embodied transcendence (agency) for the feminine being is felt to be uncertain. This uncertainty, or ambiguity of a woman's embodied agency, arises from the difficulty in achieving one's intentions using what one perceives to be an object-body for the achievement of the goals of an embodied subject. Young's suggestion that this embodied agency is ambiguous also relies on the understanding by De Beauvoir that women know themselves to be subjects in the world, despite being relegated to the status of mere object. This can be seen from her suggestion that the feminine being experiences its body as an object yet nevertheless attempts to exhibit embodied agency.

According to Young, the second mode of feminine bodily existence is an inhibited intentionality. Whereas ambiguous transcendence refers to the manner in which a woman's embodied existence enacts agency, the idea of inhibited intentionality refers 
to the embodied capacity of the feminine being to enact said agency.108 Drawing from Merleau-Ponty, intentionality can be understood as the capacity of an embodied subject to utilize its body to act in line with its intentions. Young suggests that because women are conditioned to view their bodies as primarily objects, a woman perceives her body's capacity to enact agency in contradictory ways, which leads to an inhibited intentionality. When a woman... "formulates her intentions to act upon the world, the same set of bodily possibilities which appear correlative to her intentions also appear as a system of frustrations". 109 Because of this contradictory experience of her body's capacities, feminine embodied existence is an inhibited intentionality.

Young extends her development of feminine embodied existence to a discussion on the spatiality of said existence. She argues that feminine existence lives space as enclosed or confining, as having a dual structure, and as being positioned in space.110 In relation to the first argument, Young suggests that the space which is physically available to the feminine body is frequently far greater than the space this body inhabits. According to Young, feminine existence appears to posit an existential enclosure between herself and the space surrounding her.111 This suggestion makes sense in light of Young's argument for the ways in which feminine bodily existence views its capacity to act meaningfully in the world. If I do not view my body as fully capable of meaningful action, then I will not move through the world in ways which take up the space required for said action. Furthermore, the feminine being's perception of herself as positioned

108 Young, Iris Marion, Throwing Like a Girl, 36-37.

109 Young, Iris Marion, Throwing Like a Girl, 37.

110 Young, Iris Marion, Throwing Like a Girl, 39-40.

111 Young, Iris Marion, Throwing Like a Girl, 39-42. 
within space is merely an extension of the argument by Young that a woman is trapped in a state of immanence, despite knowing herself to be a transcendent being. This state of immanence results in her perception of her bodily existence primarily as an object, and objects exist in space, they do not freely and intentionally move through it.

\section{Feminist Phenomenology: On the Importance of Agency}

As I have previously suggested, I utilize a radical feminist theoretical framework because of the particular insights it might provide into the nature of agoraphobia. The reason for developing a radical feminist phenomenological framework is the need to develop an approach which not only provides a potential consideration for why women develop the "symptoms" associated with agoraphobia, but one which also seeks to empower women to challenge claims of their state of being as "disordered". First, a phenomenological approach is useful for this goal because phenomenology is the study of how an individual experiences the world through the body. As such, it necessarily includes a discussion on the nature of embodied subjectivity and the capacity for agency. At this level of analysis, agoraphobic "symptoms" can be seen less as "things" that happen to individual women and more as experiences that are actively and knowingly constructed by the embodied subject. This then provides the potential for understanding the ways in which the subject can actively counteract such constructions of embodied experience.

Furthermore, through an application of a radical feminist phenomenology to a study of agoraphobia, the development of the lived embodiment of women in a patriarchal society is considered. Thus, along with a consideration of embodied agency, this approach allows for an appreciation of the ways in which a woman's embodied 
agency is shaped and molded by a patriarchal society. This is important because a traditional phenomenological approach considers the embodied subject as "unsexed", which has been critiqued by feminists for conflating the lived bodily experiences of men with women's experiences. A radical feminist phenomenology provides for a more nuanced understanding of the restrictions placed on a woman's embodied agency which, subsequently, provides greater potential for an understanding of women's embodied capacity to resist their labelling and classification as "disordered".

\section{ENGAGING FEMINIST PHENOMENOLOGY FROM A RADICAL FEMINIST PERSPECTIVE}

The current formulation of feminist phenomenology, as outlined by Iris Marion Young, contributes to a significant understanding of the embodied ways in which women exist in a patriarchal society. Inspired by her critical understanding of the sexed lived body, I seek to further develop insights into the manner in which women experience embodiment in a patriarchal society through a modification of her feminist phenomenological approach. In order to do this, I first outline how Hoagland's theoretical framework provides insights into the state of women's existence in a patriarchal society through the modification of De Beauvoir's feminist analysis of this existence. In particular, I argue that Hoagland's claims that women are defined as naturally vulnerable objects provides a fuller understanding of how women experience transcendence and immanence. I then move on to apply my radical feminist reading of women's existence in 
patriarchy to Merleau-Ponty's theory of the lived body in order to outline female bodily existence.

\section{Modifying Feminist Phenomenology's Feminism}

Young's use of De Beauvoir's existentialist account of women's existence in a patriarchal society is crucial for her understanding of feminine bodily existence. This account can be further developed through an application of the insights of Hoagland's ideology of protection and predation into the nature of women's existence in a patriarchal society. I utilize Hoagland's theoretical framework to modify Young's understanding of a woman's existence in two main ways. First, Hoagland's argument that women are defined as vulnerable objects suggests that women experience their state of immanence in a vulnerable fashion. Secondly, Hoagland's suggestion that women are defined as beings who are "naturally" in this state of vulnerability has implications for Young's suggestion that women are caught between a state of immanence and transcendence. Instead of suggesting that they are caught between a state of immanence and transcendence, this sense of "naturalness" implies that they experience themselves as wholly within a state of immanence.

In reference to the former, Hoagland argues, similarly to De Beauvoir, that women are defined as "other" and "object" in a patriarchal society. However, Hoagland suggests that this objectification occurs through an ideological framework which defines women as vulnerably situated. This means that she experiences her very existence as precarious and constantly open to the potential of being violated and attacked by predators. In reference to the latter, Hoagland's suggestion that women are defined as naturally vulnerable objects has implications for Young's existentialist view of women as 
trapped between a state of immanence and transcendence. A sense of being a "natural" object suggests that a woman's subjectivity is shaped and molded by her objectification. As such, her potential experience of transcendence is subsequently affected. Rather than knowing herself to be a transcendent being, as Young suggests, she knows herself to be an object, meaning the potential for transcendence is highly circumscribed.

\section{A Radical Feminist Reading of Women's Lived Bodily Experiences}

To develop my radical feminist phenomenology, an application of this modified existentialist reading of women's oppression, to Merleau-Ponty's theory of the lived body, provides an understanding of the embodied existence of women which Young observes. Merleau-Ponty suggests that there is a world for a subject insofar as the subject has a body which can act in relation to its intentions. According to Hoagland's theory, women exist in the world as "naturally" vulnerable objects. This suggests that a woman's intentionality is structured around the perceived need to "protect" the object-body from harm, thus, her ability to utilize her body to enact her own intentions in the world is highly circumscribed for two main reasons. First, the vulnerable object-body is perceived as the "self". Thus, her current "self-conception" forecloses the potential for autonomous agency through the body as it actively desires and creates the circumstances for the experience of the body as a vulnerable object. For example, women believe themselves to be object-bodies and act as if they were through sexually objectifying their bodies. According to M-P, in order to utilize the body to act in line with one's intentions one must be able to formulate one's own intentions. This formulation becomes extremely difficult when a woman's intentionality has been constructed through the idea that her body exists as a vulnerable object. Secondly, assuming that this sense of "naturalness" 
was challenged and the body was perceived as capable of autonomous agency, a woman would still perceives the ability to act out her intentions through the body as circumscribed for two reasons. First, the body would be simultaneously perceived as an object and a subject, which I suggest results in the experience of ambiguous transcendence that Young describes. Secondly, the body would be perceived as vulnerable, meaning that attempts to enact autonomous agency through the body would be met with the experience of the embodied self as threatened.

This account of female bodily existence has implications for an understanding of women's oppression in patriarchal society. It suggests that women's oppression is an oppression of the lived body which occurs as a result of women's interactions with protectors and predators. I argue that this lived bodily oppression occurs as a result of three effects of women's interactions with protectors and predators. First, protectors and predators interact with a woman's body in ways which treat the body as an object of their own intentions and goals. This results in the lived experience of one's body as if it were incapable of autonomous agency. A protector's intervention in the body's enactment of agency is done for a woman's "own good", in order to protect her from harm, whereas a predator's treatment of the body, as an object of their own intentions, is done with actual harm being enacted on the body. Because this objectification of the body occurs in relation to harm, protectors' and predators' interactions with women also result in their lived experience of the body as vulnerable. Protectors' intervention in a woman's enactment of her own bodily agency is accomplished through the suggestion that a woman's enactment of her own intentions in the world will be dangerous to her body. Predators, on the other hand, carry out their malicious intentions on the body, harming 
the body in the process. Finally, protectors and predators interact with the female body in ways which suggest that it is a naturally vulnerable object. Predators accomplish this by suggesting that a woman's bodily actions are the reasons for the harm enacted on her body whereas protectors similarly suggest that a woman's embodied actions are the reasons for the need to protect her body from harm.

\section{UNDERSTANDING AGORAPHOBIA: A RADICAL ANALYSIS OF AGORAPHOBIC EXPERIENCES}

The agoraphobic women that participated in this research study experienced their lives, prior to the full onset of their agoraphobia, in ways that I found both predictable and surprising, in light of the literature on the topic and my lived experiences with agoraphobia. I identified three themes in the early childhood experiences of agoraphobic women, all of which center around their familial relationships. I labelled these themes "family instilled a sense of danger", "threat to identity formation", and "unpredictable parental behavior". This chapter is divided into two broad sections, the first section deals with the analysis of the first two themes, through my radical feminist phenomenological framework, whereas the second section deals with my argument on the effects that the final theme has on this analysis.

In reference to the first section, I suggest that a radical feminist phenomenological reading of the themes "family instilled a sense of danger" and "threat to identity formation" provides the resources to understand these themes as capturing the role of family members in socializing agoraphobic women into female bodily existence during their early childhoods. Both themes capture the same socialization process but two different impacts of this process. The third theme, of the unpredictability of parental 
behavior, is then argued to significantly influence this socialization process by altering the manner in which women are socialized to experience lived bodily vulnerability. An appreciation of the way in which the lived female body of the "pre-agoraphobic" is socialized into female bodily existence allows for a potential reframing of the "symptoms" of agoraphobia as conditioned lived bodily responses to this socialization

process. This understanding then provides the potential resources to question two of the DSM's central claims on the "nature" of agoraphobia, that it is a pathological condition and that a fear of open spaces characterizes the lived experience of agoraphobia.

\section{ANALYZING THE EARLY LIVED EXPEREINCES OF AGORAPHOBIC WOMEN}

A thematic analysis of my interview data yielded two main reoccurring effects that agoraphobic women's familial relationships had on agoraphobic women's experiences of themselves, and the world around them, in their early childhood lives. The first is the role that agoraphobic women's interactions with family members had in ensuring that they experienced themselves as in danger whereas the second is the role that these interactions played in threatening agoraphobic women's autonomous identity formation. These familial relationships, when read through my radical feminist phenomenology, can be read as relationships which socialized young girls into aspects of female bodily existence that were the pre-conditions for agoraphobia.

My radical feminist phenomenology argues that women are socialized into female bodily existence through predators' and protectors' interactions with the female body. Both predators and protectors construct the female body in ways which suggest that it is naturally a vulnerable entity. One way in which this occurs is through the suggestion that 
women are themselves responsible for predatory attacks on the body. Thus, agoraphobic women's family members can be seen to take on roles as predators and protectors because they interact with the "pre-agoraphobic" body in ways which suggest it is naturally a vulnerable entity. Since they can be seen to take on these roles, their interactions with agoraphobic women which instill a sense of danger, and which threaten autonomous identity formation, can be understood as interactions which socialize agoraphobic women to experience aspects of female bodily existence, the body as vulnerable and the perception of the body as incapable of autonomous agency.

\section{Danger and the Socialization of Vulnerability in the Lived Body}

The agoraphobic women who were interviewed for this study experienced themselves as in danger as a result of two types of familial relationships in their early childhoods. The first type of relationship, which was experienced by five of the ten participants, was a relationship with family members who sexually and physically violated them throughout their childhoods. The second type of relationship, which was experienced by four of ten participants, was one in which family members constantly reminded them of potential dangers in the world. According to my radical feminist phenomenological framework, the former relationship can be read as a relationship with predators, who socialize women to experience their bodies as vulnerable through the sexual and physical violation of the body. The latter type of relationship can be read as a 
relationship with protectors, who socialize women to experience bodily vulnerability through the "protection" of the body from harm.

Violating the Female Body: Predators and Constructing the Lived Vulnerable Body

Half of my agoraphobic participants experienced themselves as in danger as a result of their interactions with familial predators. I suggest that these experiences of danger result from interactions with familial predators because they arise as a result of sexually and physically abusive family members in ways which suggest that agoraphobic women are "natural" victims of male predation. For example, Kori experienced a fear of sexual violation as a result of her experiences with her sexually abusive step-father, which occurred throughout the majority of her early childhood. When she was asked to describe how she experienced the sexual abuse, she described the process by which the abuse became a "normal" aspect of her life:

"It was less, ya it was less dramatic. It was just like [oh ok this again]. It's like another commercial in your show, you know [oh ok, well now I've got another 45 seconds before I can watch my show]."

This example shows how ongoing male sexual violation, from an early age, worked to naturalize Kori's experiences of sexual abuse by imposing it as simply a way of living, a daily occurrence. Kori also experienced physical abuse at the hands of her step father in ways that suggested that she was responsible for the abuse she endured: "And then, he was also physically abusive like if I didn't have dinner done when he got home at 6 o clock he would beat my ass with a belt." This feeling of responsibility is another way of 
naturalizing Kori's violation by suggesting that her actions elicit the abusive behavior, rather than the abuser himself.

Sara's uncle sexually abused her throughout her early childhood. This sexual abuse was normalized through her uncle's use of god as sanctifying a sexually exploitative relationship between himself and Sara. In this way, he can be seen as a predator because his actions aimed to convince Sara that her sexual violation was "natural", something that god desired. Ana is another example of a participant who experienced extreme physical abuse throughout her childhood. When asked why her primary caregiver, her grandmother, did not intervene in the abuse, she states that her grandmother was of the opinion that "you didn't really say anything to the men right? Like, the men were, even though it was her son, he still was like the boss in her mind". In this way, her father's abusive actions were normalized as actions which men had the "right" to do simply because they are men. Since Ana experienced her grandmother as her primary caregiver, this sense of normalization that her grandmother instilled in her resulted in Ana's experience of her physical abuse as a "normal" part of her life.

These interactions with familial predators socialized these young women to experience their bodies as vulnerable through the ongoing violation of the body. Although participants who experienced childhood sexual abuse did not provide explicit examples and details of their experiences, Kori recounts the grooming process that her sexual abuser engaged in:

"I mean looking back I think maybe he did groom me. He always bought my clothes, he always brushed my hair, he did things like that. But I didn't really have a dad so I just thought that was dad things." 
As Kori indicates, prior to her childhood experience of sexual abuse, her body was prepared for its subsequent violation through an inordinate amount of intervention in the appearance of the body by her step-father. Further examples of predators' violations of the body are through agoraphobic women's experiences of physical abuse throughout their childhoods. Two examples that highlight the experience of abuse are Ana and Clara's stories of physical abuse by their parents. Ana vividly describes her experience of the abuse, through reference to her body, when she says, "and he hit me but he hit me so hard that like all my braces were stuck to the inside of my cheek". Similarly, Clara recounts an experience of abuse by her mother which highlights the bodily aspect of the abuse:

"But my mom has beat me to the point where I've bled, she beat me to the point where I was unconscious, she almost broke my elbow with a broom. She, one time she hit me with a belt and she was hitting me with the wrong side of the belt, she was hitting me with the buckle, and didn't realize so it like, it looked like she had put it to the stove and put it to my legs, it left like big, nasty, like it burns and welts"

The effectiveness of this socialization process can be seen through my participants' examples of how they began to experience a sense of their own bodily vulnerability from an early age. For example, Ana and Nina describe constantly living in fear of being physically violated. Nina suggests that she didn't think it was an "irrational fear" to think that her father could "kill one of us". Similarly, Ana recounts living with a sense of fear 
that her father could kill her. As well, she recounts living with the constant fear of being physically attacked:

'Uhmm you know it sounds ridiculous now but that's and that's how I was like if the house was dark I would like run to wherever I was going, whatever room to turn the light on - because I just couldn't stand to be in the dark because I would always feel like someone was gonna get me — “ Kori and Clara, who both experienced childhood sexual and physical abuse, stated that they believe that the abuse led to their development of severe post-traumatic stress disorder (PTSD). A core experience of "PTSD" is the experience of reliving the traumatizing event and a marked state of hyperarousal. Clara's example of how she lived with PTSD shows how this is a lived experience of the body as vulnerable when she described how she relived the sexual abuse in her childhood: "I mean, I still have moments where I can smell his room or see things in his room and I'm 36 now it's like, I don't know if it will ever go away". Clara relives the experience of sexual assault in the present through flashbacks of her bodily experiences during the time of the assault. The experience of hyperarousal, which is associated with PTSD, is the lived experience of the body in preparation to defend itself from a similar traumatic event occurring in the present time by being "on alert".

\section{"Asking for It": Protectors and Constructing the Lived Vulnerable Body}

The second way in which my participants experienced a sense of themselves as in danger in their early childhoods is through the experience of relationships with family members as “protectors". Family members' constant reminders of potential harm were done in ways which suggested to my participants that they are "naturally" vulnerable to 
this harm. For example, Sara experienced her father as a protector because his constant warnings that "something could happen" to her were done in such a way that suggested to Sara that there was something about the fact that she was a girl that made her particularly vulnerable to being harmed. This can be seen through the fact that this potential "harm" was not applicable to her brothers:

"And then there was things like, like my brothers, my step-brothers they could go and ride their bikes around town. I was not allowed to leave the driveway, on my bike, even as a teenager because something could happen to me."

Jen experienced her mother as a protector because, throughout her childhood, her mother often told stories about the potential harms that existed for children at the hands of adults. Jen says that she often told her about the "things that adults would do to children or alluded to really dark things and didn't always tell me what they were". Her mother's suggestions of Jen's impeding vulnerability were done in such a way as to suggest that there is something about the nature of young children which makes them particularly vulnerable to being harmed. Although this is slightly different from how Sara's "protector" suggested that Sara was "naturally" vulnerable, by virtue of being a girl, both of these are examples of a process of feminization in which being "naturally" vulnerable is associated with the feminine. In the former case, it is in direct relation to being a woman while in the latter it is in the experience of being a female child.

A final example of my participants' experiences with early childhood protectors can be seen through Lena's discussion on how she experienced her relationship with her mother. Lena's mother had an intense fear of getting sick, emetophobia, which 
manifested in a compulsive need to "warn" Lena of all the potential ways in which she could get sick. When asked to provide a specific example of this, Lena recounted the story of how her mother often warned her about not eating at places she was unfamiliar with:

"Ya, definitely, definitely. Like my mom, uhm, when she went on tour ages ago she got food poisoning from rice, and so when I was younger she would always, always tell me don't eat rice from somewhere you don't know. And, but then I took that to such an extreme so like I just never ate rice."

These interactions with protectors socialized these young women to live their bodies as vulnerable as a result of the "protection" of the body from potential harms. For example, Sara's descriptions of her father's over-protectiveness describe one way in which her body was protected from harm:

"I was not allowed to leave the driveway, on my bike, even as a teenager because something could happen to me. Which, you know, my dad was very good at putting that in my head."

In this example, she experiences his over-protectiveness as a restriction on her bodily movements by not allowing her to leave the driveway alone. In this way, her body's movements through space, when not with her "protector", are constructed as potentially harmful to her body. Another example of how protectors' warnings of harm are directed towards the "protection" of the body can be seen through Lena's story of her mother's warnings not to eat at places she was not familiar with because she could get food poisoning. Here, Lena's mother is attempting to "protect" the body from getting sick by 
restricting the body's movements into certain spaces; spaces which she suggests could potentially harm the body through the experience of illness.

As a result of this socialization process, my research participants began to experience the body as a vulnerable entity. This experience can be seen through Jen's descriptions of how she lived in anxiety as a result of her relationship with her "protector":

"Like it was like what people describe when they talk about anxiety like the, in terms of stomach and heart feelings uhm but it was so strong and it was physically painful almost all the time and I was always like - fidgeting and bouncing and, you know, I was always doing things to try to get rid of it and, and as a, like I said as a child I didn't - I didn't consciously feel like fear or even anxiety most of the time but my body felt it uhm, so..."

Jen's description quite clearly highlights how this socialization process occurs through the body as she suggests that she felt vulnerable prior to becoming conscious of being vulnerable. As a result of their interactions with "protectors", both Paula and Sara experience an intensified sense of bodily vulnerability when they were not with their protectors. For example, Paula says that she was a very fearful child and provides the example of experiencing intense fear when she was required to sleep on her own, without her mother. Sara also recounts being unable to sleep on her own saying that she would “literally lay outside my parents's bedroom door crying because I did not want to sleep in my own room". In both these examples, Paula and Sara experienced the body as vulnerable when it is left on its own, evidenced by the fact that their bodies activated a 
"protective" mode by ensuring that another individual was present to "protect" them from harm.

\section{Threatening the Autonomous Self: Predators, Protectors and the Objectification of}

\section{the Body}

As outlined above, agoraphobic women's early childhood familial relationships instilled a sense of danger in the women who were interviewed for this study. Along with a sense of danger, these relationships threatened my participant's development of an autonomous self. There were two main ways in which these threats were posed; through physically and sexually abusive relationships and through the experience of controlling family members. Similarly to the radical feminist phenomenological analysis of the previous theme, these threats can be read as threats posed by predators and protectors which socialize women to experience themselves as incapable of embodied agency (read: autonomous embodied agency). Both predators and protectors achieve this socialization "goal" through the objectification of the body.

\section{Predators and Threatening the Embodied Capacity for Agency}

One way in which my participants' development of an autonomous self was threatened was through their experiences with sexually and physically abusive family members. These experiences had the effect of disconnecting them from their own interests, desires or emotions, all of which are crucial in the development of an autonomous self. As in the analysis of the vulnerability theme, this threat to autonomous self-development can be seen to occur at the hands of familial predators because it occurs as a result of sexual and physical abuse which is experienced as "normal" and "natural". Through the objectification of the body, familial predators' sexual and physical abuse of 
young women socializes them to live their bodies as having difficulty enacting autonomous agency. This objectification of the body is evident when Ana describes her experience of her father's physical abuse:

"Uhmm - and for anything, like anything that, like just if he was in a bad mood and you did something - could have been completely by accident like - didn't matter. If he was mad, or like already upset - you know, that was your butt."

In this example, Ana's body is treated as if it were merely a receptacle for her father's anger. Similarly, Kori's experience with her physically abusive step-father highlights this objectification process when she says that if she didn't have dinner ready upon his return from work "he would beat my ass with a belt". In this example, Kori's body is treated as an outlet for her step-father's anger, obliterating any sense of her own embodied agency. As previously noted, participants did not describe experiences of sexual abuse in detail but these were serious violations of their bodily integrity through the treatment of the body as an object of another's sexual desire. Thus, during the encounters participants had with their sexually abusive family members, their sense of embodied agency was obliterated through their sexual objectification.

As a result of familial predators' objectification of my participants' bodies as young women, they began to experience difficulty in enacting autonomous embodied agency, evidenced through the experience of being disconnected from aspects of the self. For example, when Kori was asked to discuss how she dealt with the physical and sexual 
abuse she experienced in her childhood, she describes a lack of embodied capacity to experience her emotions:

"It was, for - for a few years I turned off my emotions. Like I'm, I'm, I'm a very overly analytical person so I would just use my logic ok, this situation calls for me to be happy so let's be happy like everybody else is happy but I never really felt the emotion so I'm emotionally stunted as well."

Similarly, Nina describes the embodied experience of being deprived of physical sensation, as a result of her predatory father's physical abuse, when she says that the abuse resulted in her feeling "very numb during that whole-time period". I suggest that the above embodied experiences result in the difficulty of enacting embodied autonomous agency because one cannot act in relation to their desires if they are unable to experience them. Another example of a participant who experienced difficulty in enacting autonomous embodied agency is Ana, who describes how she believes that her 
father's physical abuse resulted in her experiencing her embodied self as not having permanence in the future:

"I was always anxious like, like, it sounds silly to say it now as an adult but I mean I can remember thinking [inhale] when I was young, like a little girl, I'd think to myself like oh — like I'm never going to see Christmas. Like. Something is going to happen before Christmas and I'm gonna be, kind of like any - like major thing that was coming up I would always feel like I just was never gonna see it."

I suggest that a lack of ability to perceive the embodied self as existing through time results in the difficulty of presently enacting embodied agency as embodied agency requires the potential to project an intended aim through space and time, of which the body is mobilized to carry out.

"Protectors" and Undermining the Embodied Capacity for Agency

My participants' capacity for autonomous decision making was further undermined through their early childhood experience of controlling family members. This exercise of control occurred at the hands of "protectors" because it occurred in an attempt to keep them out of harm's way. For example, Paula experienced her mother as "overbearing when it came to dealing with things. She was a bit, ya controlling in that 
way..." and suggested that this resulted in undermining her individuality. When she was asked why she believed her mother acted in such a fashion she said:

"Like I was uhm - she had a very rough childhood herself so she was very uhm she couldn't, she couldn't stand us crying and stuff so. It was just sort of, ya."

When probed for further details about her mother's childhood, Paula opened up about her mother's experiences of sexual and physical abuse as a child. This can be seen as a relationship of protection because Paula's mother's exercise of control was done in order to ensure Paula was "protected" from experiencing a similar rough childhood.

Ana's relationship with her controlling mother was also a relationship with a "protector" because her mother's "super controlling" behaviors can be read as attempts to ensure that Ana remained safe from male predation. This can be seen through Ana's description around some of the behaviors that her mother monitored:

"Literally everything. Whether or not I could use hairspray in my hair.

Whether or not I could wear, you know, makeup_or what shade of makeup

like I mean literally everything."

The fact that Ana's mother controlled her appearance, particularly the way which she presented herself as a "woman", can be seen as a way to ensure she does not present herself as "asking" for male sexual advances by wearing makeup, or the wrong kind of makeup, at an early age. Finally, Sara's relationship with her father is another example of a relationship of protection. Her father's extreme exercise of control over her life did not allow her the same freedom to make mistakes which her brothers were permitted to make. She was often punished for the same behaviors that her brothers exhibited, but 
were not punished for. This can be seen as an attempt to keep her "safe" from male predation, preparing her for the need to take responsibility for the misbehaviors of men. These actions by “protectors" undermined agoraphobic women's capacity to develop an autonomous self as a result of the intervention in the body's enactment of autonomous agency. For example, Ana's description of her protector's controlling behaviors revealed an intervention in her autonomous decision-making capacity in relation to her bodily movements:

"Like what, you know, like what you can eat or drink, when you can eat or drink, what time you went to bed, whether or not you watched tv, what time you had to get up - uhm, I had to go everywhere with her like if she, she would never leave me in the house by myself like..."

Another example of how a protector's controlling behavior intervened in the bodily capacity for autonomous agency can be seen through Vera's discussion of her mother's controlling behavior:

"Uh to uhm, especially for uh chores and anything I would do she would uhm, well anything I would say she would try to fix it and she wouldn't let me do much in the house. She would uh, always complain about things I would do around the house."

Lena's mother's controlling behaviors intervened in her capacity for embodied agency through the use of mentally coercive tactics. Lena describes her mother as often coercing her to do what she wanted by presenting her with a few choices of which the least problematic was the one that her mother desired her to choose. Lena says that her mother 
often engaged in this behavior because she "kind of saw - the path that she hated about herself being followed in me".

As a result of protector's intervention in the enactment of autonomous embodied agency, these young women were socialized to experience difficulty in enacting embodied autonomous agency. For example, Sara describes how she often put her dad on a pedestal and, as a result, the decisions that she made required "approval" before they were expressed through embodied action:

"Like he, he was always right so when, even, even today, when I make a decision I feel this overwhelming urge like I've got to go check with him to make sure that I made the right decision."

Similarly, Paula's experience of her protector's controlling behavior resulted in her need to "always go to mom" to solve her problems. Here, again, the body is perceived as having difficulty in carrying out autonomous intentionality.

\section{UNPREDICTABILITY AND THE SOCIALIZATION INTO FEMALE BODILY \\ EXISTENCE}

The majority of the agoraphobic women who participated in this study, 8 out of 10 participants, experienced their early childhood homes as places where chaos and unpredictability reigned. In particular, these agoraphobic women experienced their childhood interactions with family members, who I have argued took on roles as protectors and predators, as highly unpredictable. Since, according to my radical feminist phenomenological framework, the role of protectors and predators is to socialize women into female bodily existence, their unpredictability in the early childhood lives of my participants can be understood to influence this socialization process by impacting the 
manner in which they are socialized to experience their bodily vulnerability. Agoraphobic women are socialized to experience bodily vulnerability in relation to the experience of a loss of control. They are socialized to perceive a lack of capacity to enact embodied agency as eliciting threats to their embodied existence. Furthermore, because of their early childhood interactions with unpredictable protectors and predators, my participants were socialized to experience "protection" from threats to their embodied existence as threatening. Their socialized embodied actions to seek "protection" from threats nevertheless continue to activate the experience of possible existential embodied erasure.

\section{Socializing the Lived Vulnerable Body in Relation to a Loss of Control}

According to my radical feminist phenomenology, all women are socialized into female bodily existence, which I have argued is a process that socializes women to experience their bodies as vulnerable, as incapable of enacting autonomous agency, and as eliciting threats to their embodied existence. Hoagland's theory suggests that women are meant to experience threats to their embodied existence when they fail to act according to their socialization, as if they are "naturally" vulnerable objects. For example, if they do not seek out a "protector", or restrict their bodily movements by remaining in the home when it is "unsafe" outside, then they are "susceptible" to bodily attacks by predators.

In order for this process of socialization to occur "effectively", however, the threats posed to embodied existence must have a sense of predictability; women must know that they will experience them when they do not abide by the "appropriate" behaviors. The participants in my research study, on the other hand, were socialized into female bodily existence through their interactions with unpredictable predators and 
protectors. This impacts the above outlined socialization process because the experience of threats to embodied existence are not consistently related to the embodied actions that my participants exhibit. As a result, these threats are experienced as out of control; agoraphobic women perceive them as threats which they cannot mobilize the embodied self to act to prevent. A lack of control becomes associated with the experience of threats to embodied existence.

For example, Clara experienced her mother's predatory attacks as unpredictable because they were sometimes related to her own actions and, at other times, they were related to the actions of her siblings:

"She didn't - she didn't know any better, she just, that's how she responded to me when she got angry she hit me. When she got angry at anybody or anything she hit me specifically, not my sister, not my brother, me."

Since Clara cannot reasonably be expected to exercise control over the embodied actions of others, in order to prevent bodily harm, I suggest that this abuse is experienced as one which she cannot mobilize her embodied self to prevent, as she might have been able to if it was directly related to her own embodied actions. Nina uses the term "chaotic" to describe her early childhood household and suggests that she experienced her predatory father's physical abuse as unpredictable because the reasons behind it were inconsistent: "I would do one thing and my parents would ignore me and I would do the same thing the next day and it would end up, like, in getting punched or getting yelled at uhm..." Similarly to Clara, Nina could not mobilize her embodied self to prevent bodily harm because she was often unaware of which of her embodied actions actually elicited the 
bodily harm in the first place. A final example can be seen in Ana's experience of her father's unpredictable physical abuse which occurred for "anything, like anything that, like just if he was in a bad mood and you did something completely by accident like - ". In this case, again, physical abuse is unrelated to the embodied actions that Ana exhibits, making it impossible for her to act to prevent it.

Whereas some of my participants primarily experienced unpredictable predatory attacks on the body, others experienced unpredictable actions of "protectors". This similarly results in an inability to mobilize the embodied self to act in ways that prevent bodily harm. For example, Paula and Lena both experienced their mothers as unpredictable protectors. Paula experienced her mother as a "protector" because her mother often intervened in Paula's autonomous agency in order to keep her safe from harm. However, Paula also experienced her mother as "unstable" and suggests that, despite perceiving her as her "protector", she experienced her as acting in violent ways towards her father. Thus, Paula experienced her embodied actions to "prevent" bodily harm, by going to her "protector", as often possibly putting her in harm's way. Similarly, 
Lena experienced her "protector" as often "very erratic" and provides the following example of this:

"For example, when my brother, he like hit his head and it was bleeding but like that happens to little boys all the, like he cracked his head open so many times, when I was growing up. But she was very much [oh my god] like screaming and crying like [help, help].”

Lena, therefore, experiences an inability to act in ways to keep her embodied self "safe" because her source of protection, her mother, acts in ways which suggest that she cannot be trusted as a safe person.

\section{Unpredictability and Socializing the Lived Female Body to Seek "Protection"}

In order for the process of socializing women into patriarchy to occur, women must only experience threats to embodied existence when they fail to "present" themselves as "naturally" vulnerable, according to the dictates of patriarchal society. If they do comply with these standards by seeking "protection", then they should not experience these threats. If they nonetheless do experience threats, then they would not experience the sought out "protection" as safe. Agoraphobic women's unpredictable predators and protectors alter this process. Because of the unpredictability of their protectors and their predators, agoraphobic women experienced threats to their embodied existence even though they complied with the dictates of patriarchal society. Thus, they experienced threats when they failed to seek "protection" and when they sought out "protection".

For example, Paula experienced her mother as her protector who always "solved" her problems in an attempt to keep Paula "safe" from bodily harm. This suggests to Paula 
that her embodied self would be threatened if she did not remain with her protector. However, Paula also experienced her protector as highly unpredictable, even violent at times. When she was asked how she felt about this unpredictability, Paula quite explicitly states that she felt "unsafe" because: “... she was my stable one. She was my - you know she was my protector type thing, I took her on as the, ya." In this way, she is socialized to perceive the need to remain physically close to her protector but to simultaneously perceive this "safety" as "unsafe".

Vera similarly experienced her mother as a "protector" who intervened in her embodied agency in order to keep her out of harm's way. As with Paula, Vera experienced her mom as unpredictable: “I don't know, she, it never really changed. She was, sometimes she was my comfort and sometimes, it was like a love-hate relationship". When she was asked to describe how she experienced her protector as not "comforting", she described how her mother would be mentally coercive. Vera experienced her mother as someone whom she should go to in order to remain safe from threats to embodied existence, yet she also experienced her as someone who often threatened her embodied existence by forcing her to do things against her will. A final example of my participants' experiences with unpredictable protectors is Lena's experiences with her mother. Lena suggests that her mother was very erratic in her behavior and that, as a result, Lena often felt like she had to "monitor" her mother's actions in order to remain "safe". Lena felt "unsafe" when her mother was erratic because her mother also acted as her "protector", 
keeping her safe from threats to embodied existence. When Lena was asked whether she felt she needed "protection" from her mother's behavior, she stated the following:

"Because if it's just me and her I, I was never scared of my mom so I was never like [oh no, please don't flip at me]. I didn't care how she treated me, I was more scared of how she treated other people and how they might react because people on the, on the estate that we lived on they were really aggressive and I was scared of them."

Unpredictable predators similarly socialized my participants to experience the bodily need to seek "protection" and to simultaneously experience this bodily "protection" as potentially eliciting threats to embodied existence. For example, Kori experienced physical violation by her predatory father when she failed to conduct the household chores and prepare his dinner on time. Thus, when she failed to conduct herself as a "feminine" being, her embodied existence was threatened. However, Kori simultaneously argues that her father was often quite unpredictable and that he treated her like an "adult all week but then on Friday, you're 12 years old and you should know your place". Thus, she experienced predatory attacks on her embodied self for failing to embody "femininity" but also for failing to act "appropriately" according to her age. At these times, then, she would have experienced the embodiment of "femininity" as also eliciting attacks since these embodied actions would be classified as not "appropriate" for her age.

Similarly, Ana experienced her father's actions as predatory because her physical violation was justified by her grandmother on the grounds that she was not obeying her father; she was not acting "feminine" and non-threatening enough. Yet, she also experienced his actions as unpredictable when she says: "could have been completely by 
accident like - didn't matter. If he was mad, or like already upset - you know, that was your butt". Thus, she experienced the need to embody "femininity", in order to remain safe from his attacks on her embodied existence, but often experienced these embodied actions as nevertheless resulting in these threats because her predator's violent attacks were not related to her embodied actions.

\section{AGORAPHOBIA AS THE EFFECTS OF UNPREDICTABLE SOCIALIZATION INTO FEMALE BODILY EXISTENCE}

The DSM's claims to the "nature" of agoraphobia as a mental disorder suggest that women's experiences with agoraphobia are "symptoms" which arise as a result of some abnormality of individual functioning. However, the recognition of the "symptoms" of agoraphobia as arising from the unpredictable socialization of women into female bodily existence, challenges the claim that agoraphobic lived experiences are evidence of an individual abnormality. In order to advance this argument, I present the claim that the various "symptoms" of agoraphobia can be seen to arise from the two main effects, outlined in the previous section, that unpredictability has on the socialization of women into female bodily existence. The agoraphobic experience of a fear of panic attacks is a result of the socialization of the lived female body to experience vulnerability in relation to a loss of control. On the other hand, agoraphobic women's restrictive bodily movements, in order to "manage" the occurrence of panic attacks, can be argued to occur as a result of their socialization to seek bodily "protection".

\section{The Agoraphobic Fear of Panic Attacks: A Conditioned Bodily Response}

A central "symptom", to the experience of agoraphobia, is a fear of having a panic attack. The DSM lists several situations and places that agoraphobic women tend to avoid 
as a result of this fear, which include open spaces, closed spaces and being in a crowd. Although the list of situations and places in the DSM are not exhaustive, the interviews I conducted with my research participants confirmed that the places listed in the DSM are central to the experience of agoraphobia. However, my interview data also suggests that other places and situations are triggering of panic attacks and, subsequently, may result in the agoraphobic avoidance that is argued to be central to the experience of agoraphobia. Although the variety and diversity of places and experiences which trigger panic attacks may appear to be random and unconnected, they have one main commonality, the perception of a loss of control as triggering of a panic attack. By highlighting how these experiences are linked through triggering a feeling of a loss of control within participants, and by delving into Davidson's phenomenological discussion of a panic attack, the agoraphobic fear of panic attacks can be understood as resulting from the socialization of women to experience bodily vulnerability in relation to a loss of control.

Fearing a Panic Attack: The Agoraphobic Fear of a Loss of Control

Central to understanding the agoraphobic fear of panic attacks as resulting from the socialization of lived bodily vulnerability in relation to a loss of control is the understanding of this fear as the fear of experiencing a loss of control. In order to advance the above claim, I draw on my participants' experiences with panic attacks, both those that are commonly experienced by the majority of agoraphobic women and those that are particular to my participants. All ten of my agoraphobic participants listed situations in which they experienced a loss of control as inducing of a panic attack. As previously argued, this experience of a loss of control is the experience of the embodied self as incapable of exerting agency over a situation. Lena, for example, suggests that a 
lot of her experiences with panic disorder revolve around her feeling out of control when she gets sick. Specifically, it is her experience of her body as trapped in place, "stuck" and unable to do anything about being ill that triggers panic attacks:

"I guess the, the main thing around it, and it kind of links all my anxiety together is a loss of control. So, for me, I need to be able, I'm constantly telling myself like [If you feel bad you can go for a walk or you can do this] or you can have a bath but for me being sick is one of those things that stops you in your tracks like, you're stuck, it's kind of like being stuck. Like I can't make myself get better quicker."

Kori presents a fascinating example in which she experiences emotions as triggering of panic attacks because of her difficulty in identifying them, which resulted in her feeling like she did not have the embodied capacity to act in relation to how she felt:

“So, my emotions were very turbulent and very confusing and I couldn't identify them - and to this day I still have trouble identifying stronger emotions or knowing how to deal with them. Which causes a lot of my panic attacks which makes my agoraphobia so bad.”

Vera's experience with panic attacks also highlights the centrality of a loss of control to the occurrence of panic attacks. For example, when she was asked to discuss the experience that triggered the full onset of her panic disorder, she suggests that her panic disorder started when she started smoking marijuana. When she was asked why she believed that smoking marijuana triggered panic attacks for her, Vera stated that it was because she experienced herself as completely out of control of her mind and her body and that this experience was terrifying for her. A final example of the centrality of control 
is when Paula states that she experiences her panic disorder as something which is fundamentally related to control: "you try to control your environment, and you feel like everything is out of control so..." According to Paula, her experience of a lack of embodied capacity to control her external environment according to her desires was often triggering of panic attacks.

The above experiences with a loss of control are particular to my participants and do not appear in the DSM as the listed situations that trigger panic attacks. However, the DSM does state that the agoraphobic fear of panic attacks revolves around a fear of specific situations in which escape, or finding help, is difficult in the event of a panic attack. Although it is not evident, at first glance, how this fear is related to the experience of a loss of control, my participant's examples of the specific situations they feared provide evidence that this fear was fundamentally related to their perception of a loss of control over their vulnerability. For example, Lena suggests that driving reduced her fear of having a panic attack in public because it allowed her to exercise control over her journey:

"I know a lot of people find driving makes their anxiety really bad but again I guess it's a control thing. I feel so much better, I'm controlling my journey like I can pull over when I want or whatever.”

According to the above example, Lena perceives being a passenger, in a moving vehicle, as a state in which her ability to control how she responds to a panic attack is significantly undermined. This is indicated by her suggestion that she can "pull over" whenever she wants, which suggests that, should a panic attack occur, she can "control" 
how she responds to it. Vera's example also highlights how the fear of panic attacks is related to a perception of a loss of control over one's vulnerability:

“...might be - a little bit more anxious than normal people now but my agoraphobia is still present like I couldn't, I could not drive an hour away from here - and I still have, a little panic attack on the highway at night when I drive back from work especially when I know that I'm stuck on the highway and I can't get out and nobody is there to, to come help me."

As with previous examples that my participants have recounted, Vera suggests that her feeling of being "stuck", or unable to exercise control over her situation, is what often results in her experience of panic attacks. This feeling of being "stuck" is related to her feeling unable to get assistance or "escape" should she experience a panic attack. Finally, Ana describes how she was often afraid of closed spaces, such as elevators, because they triggered in her the feeling that she would be unable to control her environment should a panic attack occur. This is evident when she describes the need to get into elevators only if there is someone who is "stronger" than her and who can open the doors if they fail to open, someone who can "control" the situation.

\section{Davidson and a Phenomenological Reading of The Panic Attack}

As I have outlined above, the agoraphobic fear of specific situations and places, which trigger panic attacks, can be seen as a fear of situations in which there is a perception that one is out of control of one's vulnerability. In order to fully understand how this experience is a result of my participants' socialization to experience "female" bodily vulnerability in relation to a loss of control, it is relevant to consider the experience of a panic attack as a threat to embodied existence. As I have previously 
argued, the socialization of all women's bodies as vulnerable entities is one which occurs through the experience of threats to embodied existence. As such, women live their sense of vulnerability as a vulnerability of a loss of the embodied self. Therefore, the understanding of the agoraphobic woman's panic attack, as a threat to embodied existence, allows for a reading of a fear of panic attacks as resulting from this socialization process.

Joyce Davidson presents a phenomenological reading of the agoraphobic experience of a panic attack, which she suggests is experienced as a threat to one's very embodied existence. In order to advance this claim, Davidson draws upon the common "symptoms" of panic attacks, which she suggests are thoroughly embodied experiences that revolve around a fear of a loss of the self.112 The symptoms which Davidson draws upon to make her argument include a fear of dying, a fear of having a heart attack, and a sense of depersonalization and derealisation. Davidson argues that the fear of dying and the fear of having a heart attack are both, during a panic attack, experienced as if one's embodied self is being threatened.113 This is evident when one considers the physical symptoms that accompany the psychological experience of a fear of a loss of self, rapid heart rate, trouble breathing, chest pain and feeling “shaky”. My participants' experiences with agoraphobia highlight Davidson's claim that a panic attack is experienced as a threat 
to embodied existence. For example, Sara describes experiencing a fear of dying whilst having a panic attack as a thoroughly embodied experience:

"I can still see it like it's yesterday [laughs]. And, all of a sudden like my heart started racing, I felt like I couldn't breathe and I just thought I'm going to faint and I'm going to die and nobody is going to know because my husband was working uhm in D.C at the time and, it would be like 2 hours - for him to get home."

Another participant, Morgan, describes her experience with a panic attack as an experience of a threat to embodied existence:

"They were pretty mild all things considered and it was the real classic symptoms like feeling like I'm choking and palpitations and, you know, uhm just feeling dizzy and stuff like that.”

Finally, Davidson draws on the common experiences of agoraphobic sufferers with a sense of depersonalization and derealisation during a panic attack. She suggests that these experiences are ones in which embodied existence is felt to be threatened.114 In the case of depersonalization, Davidson argues that the individual feels as if they have left the body, as if they are a detached observer of the embodied self. This feeling of having left one's body is accompanied by absolute terror and experienced as if one no longer exists. Derealisation, on the other hand, is the experience of the external world as somehow "unreal" and, subsequently, this results in questioning the existence of the embodied self.

114 Davidson, Joyce. Phobic Geographies: The Phenomenology and Spatiality of Identity. Burlington, VT: Ashgate, 2003. 
Nina's example of how she experienced depersonalization highlights the embodied nature of this experience:

"Ya, it was really, really exhausting uhm and I remember like I would wake up every morning and - as I was waking up trying to establish if I like felt like I was back in my body or not and it would just go on for — “

\section{The Agoraphobic Bodily Experience of Seeking "Safety" from Panic Attacks}

Another "symptom" of agoraphobia is the manner in which agoraphobic women attempt to regain a sense of "safety" from the perceived threats posed to them through the experience of panic attacks. There are generally two main ways in which potentially threatening environments or situations are managed by agoraphobic woman. The first way, which is typically the most common, is through the avoidance of the environment or situation which triggers a panic attack, often leading one to become housebound. In fact, the home of the agoraphobic is typically considered a "safe space". The second way is through the accompaniment of a "safe person". Thus, when agoraphobic women must encounter situations which they are afraid of they tend to feel "safer" with the accompaniment of their designated "safe person". I suggest that the agoraphobic experience of either one's home, or a specific individual, as "safe" from panic attacks, is related to the patriarchal socialization of all women to experience the need to seek "protection" from predatory attacks in two ways. The first way is through the restriction of autonomous bodily movements by remaining in the proximity of a "protector" and the 
second is through restricting bodily movements by remaining within the traditional feminine sphere of the home.

"Safe Person”, "Safe Space”: The Socialization of the Lived Female Body to Seek "Protection"

In order to advance the claim that agoraphobic "safety" seeking is related to the patriarchal socialization of the female body to seek "protection" from predators, I will first show how the need for a "safe person" is experienced as the restriction of autonomous bodily movements in order to keep oneself "safe" from panic attacks. In this way, I argue that the "safe person" is a "protector" because the goal of a "protector" is to keep one safe from threats to embodied existence and a panic attack is experienced as specifically this type of threat. For example, Ana experienced her mother as her safe person throughout the course of her agoraphobia. She describes the restriction of her autonomous bodily movements into certain spaces for the fear of having a panic attack: "I don't go get my hair done, I don't go get my nails done, I don't go shopping by myself whether it's for groceries or clothes it doesn't matter because I can't do it by myself anyway." Yet, when she is accompanied by her "safe person", this fear is significantly reduced, evidenced by the ability of the body to move freely in these spaces:

“...you know maybe I needed to get groceries and, you know my husband was working and I had no one with me to go so you know I would call her and ask her. And we did, like I mean she exclusively was the one that I went with almost all the time to do my errands and stuff like that." Sara experienced her father, and sometimes her husband, as her "safe person". When she was asked to describe how her "safe person" helped her cope with her panic attacks, she 
similarly describes the loss of autonomous bodily movements through feared spaces as a result of the fear of having a panic attack:

"Uh, before that I had always, I needed a safe, you know either my husband or my father or somebody, a safe person to come with me to the store. But, ya, during that time when I was in Georgia I was actually out doing things by myself and, and I was driving. I didn't have to have someone to drive for me, but then when we came back to Maryland uhm, the, like I said the panic attacks, they just started again and -“

A final example of how the need for a "safe person" can be viewed as the lived bodily socialization of all women to seek a "protector" can be seen through Vera's experience of her mother as a "safe person". Vera describes how her autonomous bodily movements were severely restricted as a result of her panic attacks:

"It's like I had all the panic attack symptoms, all of them and uhm for 2 weeks I couldn't even leave my mom's side. I, she, she, whenever she went to the toilet I was panicking. Uh, trying to ride a car I was panicking. I couldn't even go to school for a few weeks and that's where the agoraphobia started."

Thus, Vera experienced her body as unable to move through space unless she was accompanied by her safe person because her safe person allowed her to feel as if the panic attacks were less of a threat to her.

The second manner in which agoraphobic women seek "safety" from the experience of panic attacks is by remaining in a "safe" zone, often the home. I argue that this form of "safety seeking" arises as a result of the socialization of all women to feel 
"safe" from predatory attacks by restricting bodily movements outside of the home. For example, Kori says that at the height of her agoraphobia she restricted all bodily movements outside of her home for fear of having panic attacks:

"And I, I am, in the last 7 months or so I'm not completely housebound like I was. I'm trying to get out more like go to Walmart at 3 o'clock in the morning when nobody is going to be there just to get used to being out of the house."

Lena similarly suggests that she often restricted her bodily movements outside of the home because of the lived experience of the home as a "safe zone" from the experience of panic attacks:

“I just, again, like it just basically happened again, like I didn't leave the house at all. And if I did I could only get cabs places like I couldn't, and then, I'd basically get a cab door to door and go inside so, it was weird because that agoraphobia was very much like $-\mathrm{I}$ almost felt like the sky gave me anxiety so I was ok to go out in a car but even stepping out the car I would get a panic attack like so"

\section{CONCLUDING REMARKS}

Conrad argues that the medicalization of "human problems" was a social and political, rather than a scientific achievement. $115 \mathrm{He}$ argues that there has been a slow but steady transformation of deviance in American society, behaviors that were once defined as immoral or criminal are now given medical meanings.116 This suggestion would 
certainly explain the absence of known aetiologies for the majority of "psychiatric conditions". His argument that the current drive to medicalize is a result of claims that "interested groups" put forth117 also explains the ongoing search for the genetic or biological "causes" of many psychiatric conditions, despite any resulting evidence for such "causes". Agoraphobia is one such example; there is a strong desire to "discover" the biomedical "causes" of agoraphobia yet there is virtually no evidence to support the argument that such "causes" actually exist. Since agoraphobia is a "disorder" which mainly afflicts women, this lack of "evidence" should be a concern from a feminist perspective and has been one of the driving forces behind this research project.

Yet, if Conrad is correct, and agoraphobia has been one result of the transformation of deviance in modern American society from immorality to medicalization, then who are the "interested groups" who benefit from the current psychiatric classificatory system? The obvious claim is that psychiatric institutions and pharmaceutical companies would benefit from the over medicalization of individual "problems". However, the gendered nature in the diagnosis of agoraphobia suggests that patriarchal forces might also be at play. By examining the implications of my research results on the conceptualization of agoraphobia as a particular kind of "mental disorder", I suggest that claims to the "disordered" nature of women who have been diagnosed with agoraphobia are claims which ensure that these women remain obedient to patriarchal norms. I also consider the potential implications of my research results on both the 
effectiveness and purpose of the current treatment methods employed in the treatment of agoraphobic women.

\section{RESEARCH “FINDINGS" AND THE (RE) CONCEPTUALIZATION OF AGORAPHOBIA}

The "results" of my research project present two potential challenges to the current conceptualization of agoraphobia in the DSM, both of an ontological kind. First, they challenge the claim that agoraphobia is a mental "disorder". Secondly, they challenge the claim to the type of mental disorder that agoraphobia is argued to be, a disorder related to a fear of open spaces. In reference to the first challenge, the DSM's claim that agoraphobic lived experience should be categorized as a "mental disorder" is an assertion that these experiences result from an abnormality primarily arising from within the individual. I present a challenge to this this assertion in two ways. First, since I argue that the lived experiences of agoraphobic women arise from the effects of an unpredictable family home environment on the patriarchal socialization of women into female bodily existence, I suggest that the lived experience of agoraphobia arises from socialization processes "outside" of the individual rather than from within the individual. However, because I argue that these socialization processes construct the lived body to respond to the world in a specific manner, it appears as if they arise from within the individual.

The second manner in which my research results challenge the claim that agoraphobia results from an individual dysfunction is through my suggestion that an understanding of agoraphobic lived experiences as socialized experiences allows them to be conceptualized as understandable. This specifically challenges the claim that they 
result from a dysfunction of the individual because it allows for a contextualization of agoraphobic lived bodily responses within the environment in which the lived body was socialized. When such responses are not contextualized within this environment, the lived bodily response to fear certain situations appears to be unreasonable. The fear response appears to occur "out of nowhere". However, when the fear response of the agoraphobic woman is contextualized within the environment in which the lived body is socialized to feel vulnerable, this fear response can be viewed as reasonable in light of this socialization process.

As well as challenging the claim that agoraphobia is a "mental disorder", my research results challenge the claim about the type of mental disorder that agoraphobia is. For example, the traditional understanding of agoraphobia has been that it is a fear of “open spaces”, primarily because the fear-driven avoidance behavior that agoraphobic women exhibit is in relation to open spaces. Since the recent re-conceptualization of agoraphobia in DSM 5, the traditional understanding of agoraphobia, in which there is a central dichotomy between the safety of the home and the potential violence outside of the home, has both been challenged and maintained. For example, there is now a greater focus on the fear of having a panic attack, rather than on a fear of open spaces. However, the places which the DSM lists as common places that agoraphobic women fear having panic attacks in are still predominantly spaces outside of the home. For example, being in a crowd, being in open spaces or using public transportation are commonly listed spaces that agoraphobic women fear having panic attacks in.

My understanding of agoraphobic lived experiences as related to the unpredictable socialization of women into female bodily existence challenges the claim 
that there is something inherently about "outside" spaces that agoraphobic women fear experiencing panic attacks in. Instead, I suggest that it is the experience of a loss of control, the inability of the embodied self to act in ways to prevent its potential vulnerability, that often triggers the avoidance of particular places. This perception of a loss of control over one's bodily vulnerability is fundamentally related to the patriarchal socialization of all women to perceive themselves as vulnerable when without a "protector" or when far from the traditionally feminine "safe" space of the "home". Thus, I suggest that the agoraphobic fear of a panic attack is less about a fear of a particular space or situation and more about a fear of being away from one's "safety" net because being away from safety is experienced as if one is "out of control" over their potential bodily vulnerability. The central dichotomy in agoraphobia can then be seen as one between "safety" and "threat" rather than "outside" spaces and "home".

\section{TREATING THE AGORAPHOBIC WOMAN: HEALING OR PATRIARCHAL \\ OPPRESSION?}

The potential challenges that the research results of this project present to the current conceptualization of agoraphobia in DSM 5 raise some interesting questions about the current medical approach to treating agoraphobia. Although agoraphobia is treated through a combination of therapy and medication, medicating agoraphobic women is usually the first form of treatment prescribed.118 Interestingly, both anti-anxiety and anti-depressant drugs are effective in the treatment of agoraphobia. An understanding of agoraphobic lived experiences as arising from "outside" the individual and as

118 Hahlweg, Kurt, Wolfgang Fiegenbaum, Monika Frank, Brigitte Schroeder, and Ines von Witzleben. "Short- and Long-Term Effectiveness of an Empirically Supported Treatment for Agoraphobia." Journal of Consulting and Clinical Psychology 69, no. 3 (2001): 375-382. 
"understandable" lived bodily responses, however, raises the question of the role of medication in the "treatment" process. Does this understanding imply that medication can only supress the symptoms of agoraphobia and not "cure" the individual of her "illness"? Since my results point to the way in which the lived female body is socialized to "become" agoraphobic, the experiences of the agoraphobic woman are "individual" embodied experiences, but it is questionable whether they arise from within the individual. As a result, medicating the individual can possibly be seen as a manner in which embodied fear responses are reduced but not "cured". This would certainly "explain" the common observance that agoraphobia cannot be fully "cured" but its symptoms can be managed. Another important question that my results raise is whether the knowledge of agoraphobia as arising from a patriarchal socialization process suggests that medicating agoraphobic women is a way of masking the underlying societal oppression of the female lived body by suggesting that it is women themselves who are biologically dysfunctional.

Another well-known treatment method for agoraphobia is exposure therapy.119 Exposure therapy is based on the idea that if an agoraphobic woman exposes herself to the feared stimuli, without engaging in avoidance behaviors, she will become habituated to the agoraphobic fear response and it will gradually diminish. The key premise behind this type of therapy is that the fear response is out of proportion to the danger which the individual woman encounters and, as such, by continually exposing herself to this "danger" she will realize that there is no danger. However, if the agoraphobic fear of 
panic attacks can be re-conceptualized as "understandable", given the unpredictable patriarchal socialization context, then the fear response can be argued to be "proportional" to the early lived experiences of agoraphobic women. This raises the interesting question of whether exposure could possibly have the effect of reinforcing the fear response, rather than diminishing it, because the bodily experience of imminent danger is continually activated through the exposure of perceived threatening environments. Furthermore, does exposure therapy possibly act to ensure that women become "acclimatized" to their lived bodily oppression?

Finally, another prevalent method in the treatment of agoraphobia is cognitive behavioral therapy (CBT). 120 The idea behind CBT is that maladaptive thought patterns contribute to the problematic behaviors that individuals exhibit and that, by changing or modifying these patterns, an individual can learn to reduce the problematic emotional and behavioral response associated with the thought pattern. In relation to agoraphobia, CBT labels the "thought" that certain environments are threatening as maladaptive and as resulting in the agoraphobic fear response and avoidance behavior. Thus, in order to modify this "problematic" emotional and behavior response, CBT works to have the agoraphobic woman address and label her problematic perception of the environment as threatening in order to reduce her fear response. My research results call into question two main premises of the CBT approach in the treatment of agoraphobia. First, the idea that thoughts and the conscious mind can modify emotional and behavioral responses

120 Van Apeldoorn, Franske J., Wiljo J. P. J. Van Hout, Marieke E. Timmerman, Peter Paul A. Mersch, and Johan A. den Boer. "Rate of Improvement during and Across Three Treatments for Panic Disorder with Or without Agoraphobia: Cognitive Behavioral Therapy, Selective Serotonin Reuptake Inhibitor Or both Combined." Journal of Affective Disorders 150, no. 2 (2013): 313-319. 
rests on the problematic assumption that the mind controls how the body acts and feels. My understanding of agoraphobic lived experiences as socialized experiences of the lived body suggests that agoraphobic women experience the fear response through the experience of the lived body as vulnerable. This suggests that it is the body which is central in the experience of "problematic" agoraphobic behavioral and emotional experiences. As such, the mind does not control the body, the mind is activated through the experiences of the body. This understanding suggests that attempting to modify bodily fear responses through active monitoring of thought patterns potentially fails to acknowledge the "knowledge" the female lived body has of its own oppression and traps the individual in the "oppressed" mind.

Secondly, my results raise questions about the assumption in CBT that the thought patterns of agoraphobic woman are "maladaptive". I argue that these thought patterns arise as a result of women's socialization to experience their bodies in a particular fashion and that this suggests that these thoughts can be argued to be "understandable" rather than "abnormal". Although this challenges the claim that they are "unreasonable", I do suggest that these thoughts are "maladaptive" to the current environment in which the agoraphobic woman finds herself, however, I suggest that they are "maladaptive" thoughts of a socialization process. This claim is significantly different because the claim that they are of the individual contributes to a process of self-blame within the individual woman for a failure to "modify" these thoughts. This can exacerbate the current tendency of women in a patriarchal society to overly attribute responsibility to 
themselves for failures which should, more properly, be attributable to patriarchal society.

This research project calls for a radical disruption in our current conceptualization of agoraphobic women as mentally ill. It is my hopes that by examining agoraphobic lived experiences through a radical feminist phenomenology that the importance of the knowledge that the lived body holds of its oppression can become integral to the "treatment" of agoraphobia. I suggest that an engagement with broader patriarchal structures is necessary in order to get to the root of the healing required for the agoraphobic woman and that an approach that considers the lived body places this healing process firmly within her control. 


\section{BIBLIOGRAPHY}

Bankey, Ruth. 2001. La donna é mobile: Constructing the irrational woman. Gender, Place \& Culture 8 (1).

Bekker, Marrie H. J. 1996. Agoraphobia and gender: A review. Clinical Psychology Review 16 (2).

Bondi, Liz and Erica Burman. "Women and Mental Health: A Feminist Review." Feminist Review 68, no. 68 (2001).

Bordo, Susan, 1947. 1993. Unbearable weight: Feminism, western culture, and the body. Berkeley: University of California Press.

Braun, Virginia and Victoria Clarke. "Using Thematic Analysis in Psychology." Qualitative Research in Psychology 3, no. 2 (2006).

Brown, Laura S. and Mary B. Ballou 1949. Rethinking Mental Health and Disorder: Feminist Perspectives. New York, N.Y: Guilford Press, 2002.

Bryman, Alan and Melissa A. Hardy 1952. Handbook of Data Analysis. London;Los Angeles, [Calif.];: SAGE, 2004.

Busfield, Joan and Jo Campling. Men, Women, and Madness: Understanding Gender and Mental Disorder. Washington Square, N.Y: New York University Press, 1996.

Cancian, Francesca M. "Feminist Science: Methodologies that Challenge Inequality." Gender and Society6, no. 4 (1992).

Caplan, Paula J., Joan McCurdy-Myers, and Maureen Gans. "Should 'Premenstrual Syndrome' be Called a Psychiatric Abnormality?" Feminism \& Psychology 2, no. 1 (1992).

Caplan, Paula J., 1947 and Lisa Cosgrove. Bias in Psychiatric Diagnosis / Edited by Paula J. Caplan and Lisa Cosgrove. Lanham, Md: Jason Aronson, 2004.

Campbell, Rebecca, Adrienne E. Adams, Sharon M. Wasco, Courtney E. Ahrens, and Tracy Sefl. "“What has it been Like for You to Talk with Me Today?": The Impact of 
Participating in Interview Research on Rape Survivors." Violence Against Women 16, no. 1 (2010).

Chesler, Phyllis. Women and Madness. 1st, rev. and updat ed. New York, N.Y: Palgrave Macmillan, 2005.

Conrad, Peter, 1945 and Joseph W. Schneider 1943. Deviance and Medicalization: From Badness to Sickness. New York: Macmillan, 1980. Cancian, Francesca M. "Feminist Science: Methodologies that Challenge Inequality." Gender and Society 6, no. 4 (1992):

Cornacchio, Danielle, Tommy Chou, Hayley Sacks, Donna Pincus, and Jonathan Comer. 2015. clinical consequences of the revised dsm-5 definition of agoraphobia in treatmentseeking anxious youth. Depression and Anxiety 32 (7): 502-8.

Cotterill, Pamela. "Interviewing Women: Issues of Frienship, Vulnerability, and Power." Women's Studies International Forum 15, no. 5 (1992).

Cotten, Christopher, and John W. Ridings. 2011. Getting Out/Getting in: The DSM, political activism, and the social construction of mental disorders. Social Work in Mental Health 9 (3).

Davidson, Joyce, 1971. 2003. Phobic geographies: The phenomenology and spatiality of identity. Burlington, VT: Ashgate.

Davidson, Joyce. 2001. Pregnant pauses: Agoraphobic embodiment and the limits of (im)pregnability. Gender, Place \& Culture 8 (3).

Deakin, Hannah and Kelly Wakefield. "Skype Interviewing: Reflections of Two PhD Researchers." Qualitative Research 14, no. 5 (2014).

Devault, Marjorie L. "Talking and Listening from Women's Standpoint: Feminist Strategies for Interviewing and Analysis." Social Problems 37, no. 1 (1990).

DeVault, Marjorie L. "Talking Back to Sociology: Distinctive Contributions of Feminist Methodology." Annual Review of Sociology 22, no. 1 (1996).

Dodd, Jenifer. 2015. "The name game": Feminist protests of the DSM and diagnostic labels in the 1980s. History of Psychology 18 (3)

Drescher, Jack. 2015. Out of DSM: Depathologizing homosexuality. Behavioral Sciences (Basel, Switzerland) 5 (4). 
Fahs, Breanne. "Ti-Grace Atkinson and the Legacy of Radical Feminism." Feminist Studies37, no. 3 (2011).

Farrell, Janine and Thea Cacchioni. "The Medicalization of Women's Sexual Pain." Journal of Sex Research 49, no. 4 (2012).

Firestone, Shulamith. 1970. The Dialectic of Sex: The Case for Feminist Revolution. New York: Morrow.

Gelfond, Marjorie. 1991. Reconceptualizing agoraphobia: A case study of epistemological bias in clinical research. Feminism \& Psychology 1 (2): 248.

Gorelick, Sherry. "Contradictions of Feminist Methodology." Gender and Society 5, no. 4 (1991).

Griffin, Gabriele. 2012. "The Compromised Researcher: Issues in Feminist Research Methodologies." Sociologisk Forskning 49 (4).

Hahlweg, Kurt, Wolfgang Fiegenbaum, Monika Frank, Brigitte Schroeder, and Ines von Witzleben. "Short- and Long-Term Effectiveness of an Empirically Supported Treatment for Agoraphobia." Journal of Consulting and Clinical Psychology 69, no. 3 (2001).

Hesse-Biber, Sharlene Nagy. Handbook of Feminist Research: Theory and Praxis. Second ed. Thousand Oaks, California: SAGE Publications, 2012.

Holmes, Joshua. "Space and the Secure Base in Agoraphobia: A Qualitative Survey." Area 40, no. 3 (2008).

Jacobson, Kirsten. 2011. Embodied domestics, embodied politics: Women, home, and agoraphobia. Human Studies 34 (1).

Jimenez, Mary Ann. "Gender and Psychiatry: Psychiatric Conceptions of Mental Disorders in Women, 1960-1994." Affilia 12, no. 2 (1997).

Klein, Renate, 1945 and Gloria Bowles. Theories of Women's Studies. London;Boston;: Routledge \& Kegan Paul, 1983.

Lester, Rebecca J. "Lessons from the Borderline: Anthropology, Psychiatry, and the Risks of being Human." Feminism \& Psychology 23, no. 1 (2013).

MacKinnon, Catharine A. Toward a Feminist Theory of the State. Cambridge, Mass: Harvard University Press, 1989. 
Malbos, Eric, Ronald M. Rapee, and Manolya Kavakli. "Isolating the Effect of Virtual Reality Based Exposure Therapy for Agoraphobia: A Comparative Trial." Journal of CyberTherapy and Rehabilitation 4, no. 2 (2011): 199.

Margraf, Jürgen, Anke Ehlers, and Walton T. Roth. 1986. Biological models of panic disorder and agoraphobia-A review. Behaviour Research and Therapy 24 (5).

Maria Mies, "Towards a Methodology for Feminist Research" in Theories of Women's Studies, ed. Gloria Bowles and Renate Duelli Klein (London; Boston: Routhledge \& Kegan Paul, 1983).

Mauthner, Natasha. "I. Towards a Feminist Understanding of `Postnatal Depression." Feminism \& Psychology 3, no. 3 (1993).

Miriam, Kathy. "Toward a Phenomenology of Sex-Right: Reviving Radical Feminist Theory of Compulsory Heterosexuality." Hypatia 22, no. 1 (2007).

Petry, Nancy M., and Charles P. O'Brien. 2013. Internet gaming disorder and the DSM5. Addiction 108 (7): 1186-7.

Reuter, Shelley Zipora. 2001. 'The very opposite of calm': A socio -cultural history of agoraphobia. ProQuest Dissertations Publishing.

Rich, Adrienne Cecile. "Compulsory Heterosexuality and Lesbian Existence (1980)." Journal of Women's History 15, no. 3 (2003).

Sarah Lucia Hoagland, "Moral Revolution: From Antagonism to Cooperation" in Feminism and Philosophy: Essential Readings in Theory, Reinterpretation, and Application, ed Nancy Tuana and Rosemarie Tong (Boulder, Colo: Westview Press, 1995)

Shaw, Clare and Gillian Proctor. "I. Women at the Margins: A Critique of the Diagnosis of Borderline Personality Disorder." Feminism \& Psychology 15, no. 4 (2005).

Staub, Michael E. 2011. Madness is civilization: When the diagnosis was social, 19481980. Chicago: University of Chicago Press.

Svenaeus, Fredrik, Institutionen för kultur och lärande, Centrum för praktisk kunskap, and Södertörns högskola. "Anorexia Nervosa and the Body Uncanny: A Phenomenological Approach." Philosophy, Psychiatry, \& Psychology 20, no. 1 (2013).

Tong, Rosemarie and Nancy Tuana. Feminism and Philosophy: Essential Readings in Theory, Reinterpretation, and Application. Boulder, Colo: Westview Press, 1995. 
Turgeon, Lyse, André Marchand, and Gilles Dupuis. "Clinical Features in Panic Disorder with Agoraphobia: A Comparison of Men and Women." Journal of Anxiety Disorders 12, no. 6 (1998).

Ussher, Jane M. "Diagnosing Difficult Women and Pathologising Femininity: Gender Bias in Psychiatric Nosology." Feminism \& Psychology 23, no. 1 (2013).

Ussher, Jane M. "The Role of Premenstrual Dysphoric Disorder in the Subjectification of Women." Journal of Medical Humanities 24, no. 1 (2003).

Van Apeldoorn, Franske J., Wiljo J. P. J. Van Hout, Marieke E. Timmerman, Peter Paul A. Mersch, and Johan A. den Boer. "Rate of Improvement during and Across Three Treatments for Panic Disorder with Or without Agoraphobia: Cognitive Behavioral Therapy, Selective Serotonin Reuptake Inhibitor Or both Combined." Journal of Affective Disorders 150, no. 2 (2013).

Van Riel, Raphael. 2016. What is constructionism in psychiatry? from social causes to psychiatric classification. Frontiers in Psychiatry 7.

Warner, Sam, Paula Reavey, and Taylor \& Francis Group. 2003. New feminist stories of child sexual abuse: Sexual scripts and dangerous dialogues. London: Routledge.

Wittchen, Hans-Ulrich, Andrew T. Gloster, Katja Beesdo-Baum, Giovanni A. Fava, and Michelle G. Craske. 2010. Agoraphobia: A review of the diagnostic classificatory position and criteria. Depression and Anxiety 27 (2).

Young, Iris Marion and Oxford University Press. 2005. On Female Body Experience: "Throwing Like a Girl" and Other Essays. New York: Oxford University Press. 